\title{
MoRfoANATOMIA DE ESPÉCIES BRASILEIRAS DE OXYPETALUM (ASCLEPIADOIDEAE-APOCYNACEAE) ${ }^{1}$
}

\author{
Nilda Marquete F. Silva ${ }^{2,4,6}$, Maria da Conceição Valente ${ }^{2}$, Jorge Fontella Pereira, \\ Gilberto Menezes Amado Filho ${ }^{2,4} \&$ Leonardo R. Andrade
}

\section{RESUMO}

(Morfoanatomia de espécies brasileiras de Oxypetalum (Asclepiadoideae-Apocynaceae). É apresentado o estudo morfoanatômico dos 25 táxons do gênero Oxypetalum, que reúne cerca de 130 espécies distribuídas na América Central e América do Sul. O presente trabalho apresenta a morfologia externa da flor juntamente com aspectos anatômicos, sob microscopia óptica e microscopia eletrônica de varredura (MEV). Presença de feixes bicolaterais, idioblastos cristalíferos e, nas regiões intersepalares, de coléteres são assinaladas. A corona consiste de cinco segmentos parenquimatosos vascularizados ou não. No que concerne ao estabelecimento dos transladores (retináculo e caudículas), verifica-se que são formados pela substância viscosa exsudada pelas células secretoras que revestem a cabeça estilar. Esses resultados possibilitam uma melhor compreensão das características florais e reconhecimento dos táxons dentro do gênero, principalmente a partir das variações observadas na corona, polinários e apêndices estilares.

Palavras-chave: morfologia, anatomia, coléteres e transladores, Asclepiadaceae, MEV.

\section{Abstract}

(Morpho-anatomy of Brazilian species of Oxypetalum (Asclepiadoideae-Apocynaceae). The morphoanatomical studies in 25 taxa of Oxypetalum are presented. The genus comprises about 130 species distributed in Central and South America. The external morphology of the flower was studied together with the anatomic and SEM analysis, to provide better understanding of these organs. The presence of bicollateral bundles, crystalliferous idioblasts and sepals with colleter was observed. The corona consists of five parenchymatous lobes with or without vascularization. The translators (retinaculum and caudicula) are formed from a viscous exsudate of the secretory cells which cover the stylar head. These results enhance the understanding of the floral characteristics and can be used towards the identification of the taxa within the genus, mainly considering the distinct morphology of corona, pollinaria and style appendage.

Key words: morphology, anatomy, collecter and translators, Asclepiadaceae, SEM.

\section{INTRODUÇÃOO}

Asclepiadoideae está representada por 250 gêneros e de 2.000 a 3.000 espécies (Rapini et al.2001), distribuídos nos trópicos e subtrópicos, especialmente da América do Sul e África do Sul. No Brasil, assinalam-se cerca de 38 gêneros e 492 espécies, com preferência, principalmente, pelas formações vegetacionais das florestas secundárias e regiões de campo e cerrado (Barroso et al. 1986). O estudo das espécies desta subfamília desperta interesse, principalmente, pela distinção morfológica de suas flores, consideradas entre as mais complexas nas Angiospermas.
De acordo com Endress (1994), nas flores de Asclepiadoideae ocorre uma fusão, não somente entre membros do mesmo elemento estrutural, como também entre verticilos diferentes, principalmente estames e carpelos. Apesar de apresentarem em suas flores todos os verticilos comuns à maioria das Angiospermae, as Asclepiadoideae são caracterizadas por um conjunto de modificações correspondentes a soldaduras organizadas, que vão originar estruturas diferentes com alterações de funções.

Artigo recebido em 08/2006. Aceito para publicação em 03/2008.

${ }^{1}$ Parte da Tese de Doutorado do primeiro autor apresentada na UFRJ - Museu Nacional.

${ }^{2}$ Pesquisadores do Instituto de Pesquisas Jardim Botânico do Rio de Janeiro.

${ }^{3}$ Pesquisador do Museu Nacional.

${ }^{4}$ Bolsistas do CNPq.

${ }^{5}$ Pesquisador do Laboratório de Biominalização do Instituto de Ciências Biológicas CCS/UFRJ.

${ }^{6}$ Autor para correspondência:nmarquet@jbrj.gov.br 
Os verticilos florais surgem inicialmente como nas demais Angiospermae. Entretanto, a partir de fusões congênitas e posgênitas originam-se outros elementos como, por exemplo, a corona que resulta da fusão congênita da corola e do androceu. Por outro lado, o ginostégio e o polinário, assim como a trilha de guia (armadilha para os insetos visitantes), surgem em conseqüência da soldadura posgênita do androceu com o gineceu (Endress 1994).

A corona e os transladores são formados num estádio mais tardio do desenvolvimento da flor. Segundo Kunze (1990) e Endress (1994), quanto à morfologia externa, a corona se desenvolve após a corola e androceu terem alcançado um estádio avançado de desenvolvimento.

O gênero Oxypetalum está representado por cerca de 130 espécies neotropicias (Rapini et al. 2001). No Brasil, ocorrem cerca de 115 espécies, distribuídas principalmente na floresta pluvial atlântica, na restinga, nos campo rupestres, em campo altimontanos e em floresta secundária.

Oxypetalumé bem definido, embora suas espécies apresentem ampla variabilidade morfológica, o que dificulta consideravelmente a delimitação das mesmas. Caracteriza-se por apresentar flores caudículas expandidas com uma membrana provida de dente (apêndice espessado) exserto ou incluso, ginostégio séssil ou subséssil, segmentos da corona inseridos no tubo da corola e no tubo estaminal, corona de origem corolina e estaminal e apêndice estilar mais ou menos bífido, crateriforme ou aplanado (Marquete 2003).

Neste trabalho são explorados aspectos morfológicos e anatômicos dos órgãos vegetativos e reprodutivos de Oxypetalum visando, principalmente, tornar mais compreensível a morfologia de suas flores. Pretende-se também complementar com dados morfoanatômicos o estudo taxonômico de espécies de Oxypetalum realizado por Marquete (2003) e Marquete et al. (2007), contribuindo para um conhecimento do gênero.

\section{Materiale Métodos}

O estudo foi baseado em análise morfológica comparativa das estruturas vegetativas, florais e do fruto em 25 táxons relacionados a seguir: $O$. alpinum (Vell.) Fontella \& E.A.Schwarz var. alpinum, $O$. appendiculatum Mart., O. arachnoideum E.Fourn., O. banksii Schult. subsp. banksii, O. banksii subsp. corymbiferum (E.Fourn.) Fontella \& C.Valente, O. cordifolium (Vent.) Schltr. subsp. brasiliense (Decne.) Fontella \& Goyder, O. cordifolium (Vent.) Schltr. subsp. pedicellatum (Decne.) Fontella \& Goyder, $O$. costae Occhioni, O. glaziovianum Loes., $O$. glaziovii (E.Fourn.) Fontella \& Marquete, $O$. insigne (Decne.) Malme var. insigne, $O$. insigne var. glabrum (Decne.) Fontella \& E.A.Schwarz, O. insigne var. glaziovii (E.Fourn.) Fontella \& E.A.Schwarz, O. jacobinae Decne., O. lanatum Decne. ex. E.Fourn., O. lutescens E.Fourn., O. molle Hook. \& Arn., O. pachyglossum Decne., O. pannosum Decne. var. pannosum, O. patulum E.Fourn., $O$. pilosum Gardner, O. regnellii (Malme) Malme, O. schottii E.Fourn., O. sublanatum Malme e O. wightianum Hook. \& Arn., provenientes de vasto material cedido por empréstimo dos seguintes herbários: BHCB, BOTU, CEN, CVRD, ESA, ESAL, F, GFJP, GUA, HB, HBR, HRB, HRCB, HUEFS, IBGE, INPA, MBM, NY, OUPR, PAMG, R, RB, RBR, RFA, RUSU, UB, UFG, S, SP, SPF e TER (Holmgren et al. 1990) ou de coletas efetuadas pelos autores.

Para a análise histológica das estruturas florais, botões em vários estádios de desenvolvimento de $O$. banksii subsp. banksii e O. insigne var. insigne provenientes da restinga do Grumari no Rio de Janeiro e em Minas Gerais, no Município de Ouro Preto (J.A. Jesus 1326 e 1491 - RB) e N.Marquete et al. $295(\mathrm{RB})$ respectivamente, foram fixados em FAA 70\% (Johansen 1940). O material foi incluído em parafina e processado de acordo com as técnicas usuais para estudos anatômicos (Johansen 1940). As lâminas permanentes foram coradas com o azul de astra e fucsina básica (Luque et al. 1996). Efetuaram-se 
testes histoquímicos, em botões florais recém coletados, para comprovar a presença de cutina e lignina, a natureza dos cristais e a presença de néctar. Foram utilizados sudan IV para evidenciar cutina, floroglucina em meio ácido para indicar a presença de lignina (Sass 1940), e os ácidos acético glacial, clorídrico e sulfúrico diluídos para detectar o oxalato de cálcio (Johansen 1940) e a presença de açúcares, comprovada pelo reagente de Fehling (Purvis et al. 1964).

As observações do indumento e coléteres nas diferentes estruturas florais, ao microscópio eletrônico de varredura, foram executadas em O. insigne var. insigne, O. insigne var. glaziovii e $O$. appendiculatum (N. Marquete et al. 369, 450 e 293 - RB). Para tanto, fragmentos do botão floral foram fixados em paraformaldeído $4 \%$ e glutaraldeído 2,5\%, em tampão PIPES O,1 M (pH=7.3). Após a fixação, o material foi lavado em tampão e posteriormente desidratado em série crescente de acetona até 100\% (Hayat 1981), seguindose a secagem no aparelho de ponto crítico (Balzers/Union CPD 020). As amostras foram então montadas diretamente em suportes de alumínio, metalizadas com ouro e observadas em microscópio de varredura JEOL 5310, operado em $20 \mathrm{kV}$.

Para análise da vascularização das peças florais, flores herborizadas e re-hidratadas, de todos os táxons foram clarificadas com hidróxido de sódio $5 \%$ durante dois dias. A seguir, o material foi lavado em água destilada, corado com safranina $5 \%$ e montado entre lâmina e lamínula, em glicerina 50\%. As observações e os desenhos foram realizados ao microscópio óptico equipado com câmaraclara e os desenhos das lacínias da corola em microscópio estereoscópio. Somente $O$. costae, O. glaziovianum $O$. lutescens e $O$. schottii não foram estudadas tendo em vista o material estar mal representado nos herbários consultados ou tratar-se de tipo nomenclatural.

A morfologia dos polinários foi analisada em todos os táxons, exceto em $O$. lutescens representada apenas pela coleção-tipo. Para esta análise utilizou-se material herborizado. As flores foram hidratadas e os polinários removidos para mensuração das estruturas (retináculo, caudículas e polínias), em até quinze polinários por espécie, dependendo da disponibilidade do material. Em seguida, os polinários foram submetidos ao hidróxido de sódio $2 \%$, até a completa clarificação, e posteriormente lavados em água destilada. $\mathrm{O}$ material citado foi então medido com relação ao comprimento e a largura dos retináculos e polínias, bem como quanto ao comprimento das caudículas, dentes e pedículos.

Os desenhos foram realizados em microscópio óptico Carl Zeiss equipado com câmara-clara. Nas figuras da morfologia externa, vascularização das peças florais, polinários e eletromicrografias, citou-se o material utilizado pelo nome e número do coletor.

\section{Resultados e Discussão}

Hábito de crescimento: A maioria dos táxons aqui estudados possui porte volúvel (Tab. 1, Fig. 1a); apenas O. patulum (Fig. 1b) apresenta porte ereto. Segundo observações de coletores, registradas em etiquetas de herbário, as espécies de Oxypetalum apresentam porte ereto em vegetação de campo, campo altimontano, campo rupestre e cerrado e em geral são volúveis em floresta secundária, cerrado, restinga e campo.

Sistema radicular: como observado para $O$. glaziovii, o sistema radicular é axial, possui cor amarelo-pálida e é por vezes tuberoso profundo e com raízes secundárias horizontais (Fig. 1c-d).

Fontella-Pereira et al. (1984), estudando as espécies de Oxypetalum ocorrentes em Ouro Preto (MG), registram a presença de xilopódio para $O$. strictum subsp. strictum; entretanto essa ocorrência não foi confirmada neste estudo.

Caule: em todos os táxons estudados os caules variam entre volúveis (Fig. 1e-f) e eretos, sempre com base sublenhosa. Porém, para o gênero, tem-se registros de espécies com 
Morfoanatomia de espécies brasileiras de Oxypetalum

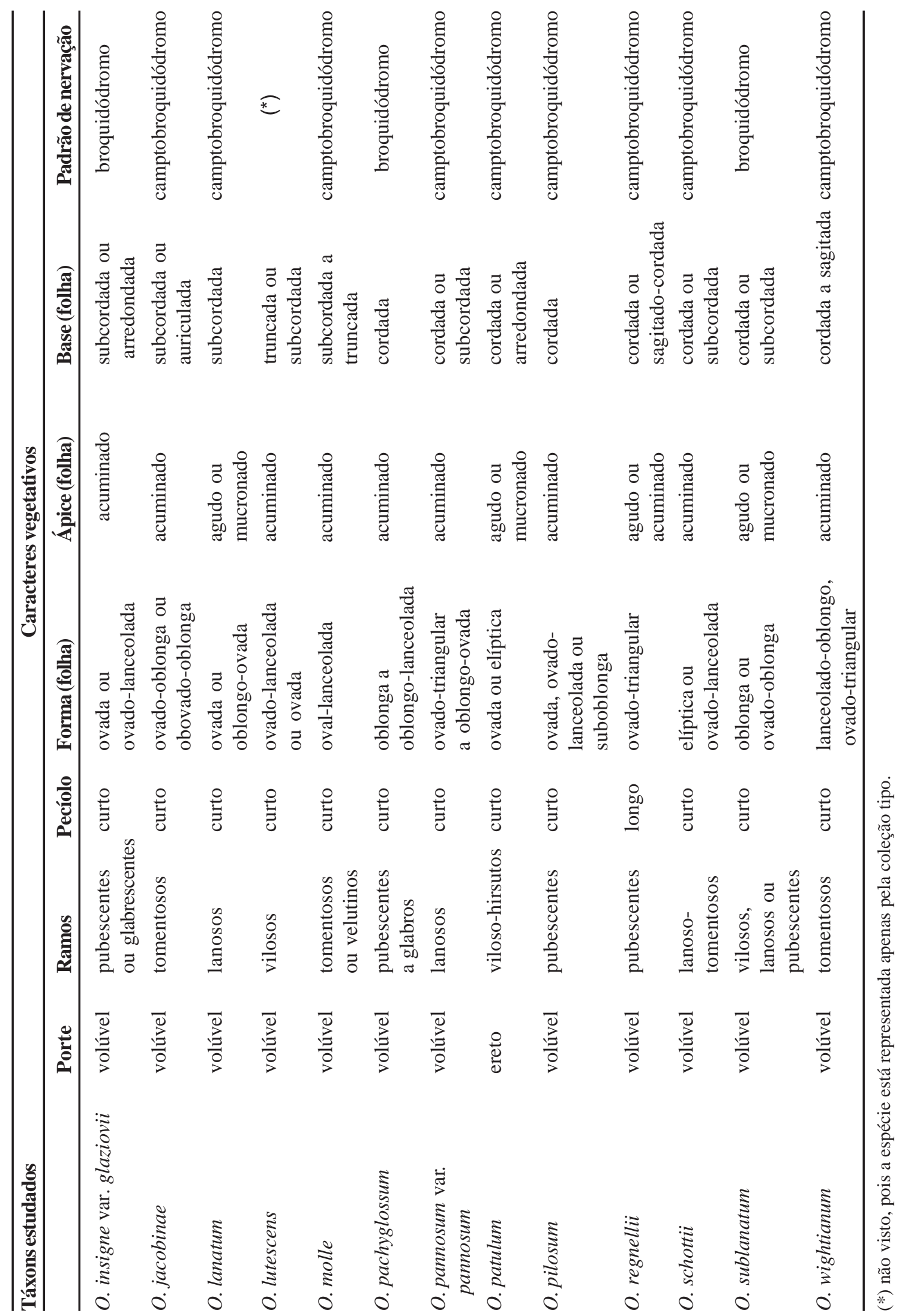



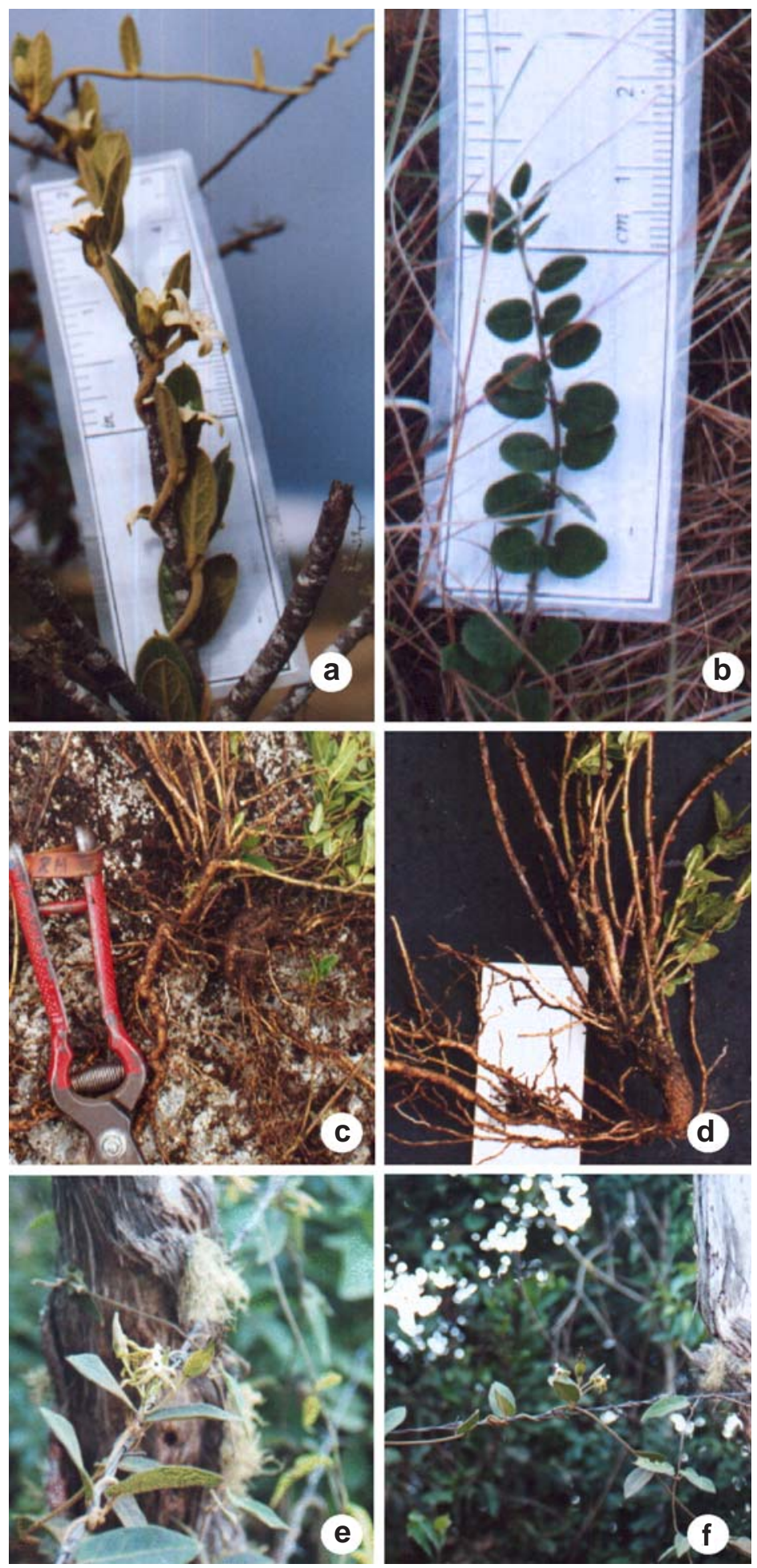

Figura 1 - Tipos habito, sistema radicular e ramos. a. hábito ereto de Oxypetalum patulum (Marquete 340); b. hábito volúvel de O. lanatum (Marquete 354); c-d. O. glaziovii - c. sistema radicular; d. raiz axial com uma torção e prosseguindo o seu desenvolvimento horizontal à superfície (Marquete 451); e-f.ramos volúveis de O. insigne var. glaziovii (Giordano 2476). 
caules herbáceos, os quais podem ser suberetos, prostrados ou reptantes.

O látex presente em todos os órgãos da planta é leitoso, abundante e de cor branca. Segundo Solereder (1908), Occhioni (1956), Metcalfe \& Chalk (1965), Fontella-Pereira et al. (1971) e Valente et al. (1971) os caules das Asclepiadoideae possuem tubos laticíferos articulados.

Os ramos são sinistrorsos e se enrolam em arbustos ou pequenas árvores, atingindo de 0,5 a 8 metros de altura.

Folhas: as folhas são simples, opostas, com pecíolos (Fig. 2) curtos $(0,3-4 \mathrm{~cm})$ ou longos (1-7,2 cm). As lâminas, de tamanho variado, são largas a lineares, e possuem ápices agudos, acuminados, mucronados e às vezes caudados; a base é freqüentemente cordada, podendo ser também auriculada, subcordada ou arredondada (Tab. 1, Fig. 2a-k). A consistência é variável, predominando a papirácea ou membranácea, podendo ocorrer também folhas coriáceas.

Possuem 1-3 ou mais coléteres, em posição adaxial, na base da folha, próximo ao ponto de inserção do pecíolo. Estas estruturas, que podem ser digitiformes, subcilíndricas ou cônicas são denominadas "emergências glandulares" por Fontella-Pereira et al. (1971) e Fontella-Pereira (1977), "glândulas" por Decaisne (1844), Fournier (1885), Malme (1927, 1939), Meyer (1944) e Occhioni (1956) e "pêlos glandulares" por Fontella-Pereira \& Marquete (1971) e Valente et al. (1971).

Fontella-Pereira \& Marquete (1974, 1975) observaram a ocorrência de tais emergências, não na base da face adaxial da lâmina foliar, mas lateralmente na base dos pecíolos. Essas emergências são também consideradas coléteres por Rapini et al. (2001) e Schwarz \& Furlan (2002) ou nectários extraflorais por (Arekal \& Ramakrishna 1980).

Em $O$. insigne var. insigne os coléteres foliares são constituídos por uma epiderme uniestratificada de células secretoras em paliçada, as quais mostram-se recobertas por uma camada cuticular delgada; abaixo da epiderme observa-se um tecido parênquimático de células heterodimensionais.

Rio et al. (2002) evidenciaram a presença de mucilagem nos coléteres foliares de Prestonia coalita. A atividade secretora está relacionada à função destas estruturas que é proteger as gemas e, consequientemente, os meristemas (Fahn 1979).

O padrão de nervação pode ser do tipo camptobroquidódromo ou broquidódromo (Tab. $1)$.

Inflorescência: as inflorescências das espécies de Oxypetalum estudadas são monotélicas e ocorrem em posição subaxilar sendo providas apenas de prófilos. São dos tipos dicásio siadióides corimbiforme (Fig. 3a), dicásio siadióides umbeliforme (Fig. 3b), cimóide corimbiforme (Fig. 3c) e siadióide (Fig. 3d) (Tab. 2).

As inflorescências de Asclepiadoideae têm sido caracterizadas como sistemas terminais tirsóidais (Liede \& Weberling 1995). Aparecem em posição subaxilar, pois são originadas no ápice do ramo e deslocadas lateralmente pelo desenvolvimento da gema vegetativa que dá continuidade ao ramo principal, compondo um sistema simpodial (Rapini et al. 2001). A partir desse padrão básico, o tirsóide sofre várias reduções de seus entrenós basais, com redução também no número de flores, resultando em siadióides (Troll 1964; Weberling 1989).

Flor: são actinomórficas, completas, isostêmones, pentâmeras e possuem ovário súpero formado por dois carpelos livres.

O cálice é de cor verde ou esverdeada curtamente fusionado na base e dividido em cinco sépalas, com prefloração valvar, quincuncial ou imbricada. As sépalas são freqüentemente glabras na face adaxial e com denso indumento na face abaxial em $O$. insigne var. insigne (Fig. 4a).

Em $O$. insigne var. insigne, cada lacínia possui epiderme uniestratificada formada por células heterodimensionais e revestidas por uma camada cuticular delgada e lisa; ocorrem tricomas pluricelulares apenas na face abaxial 

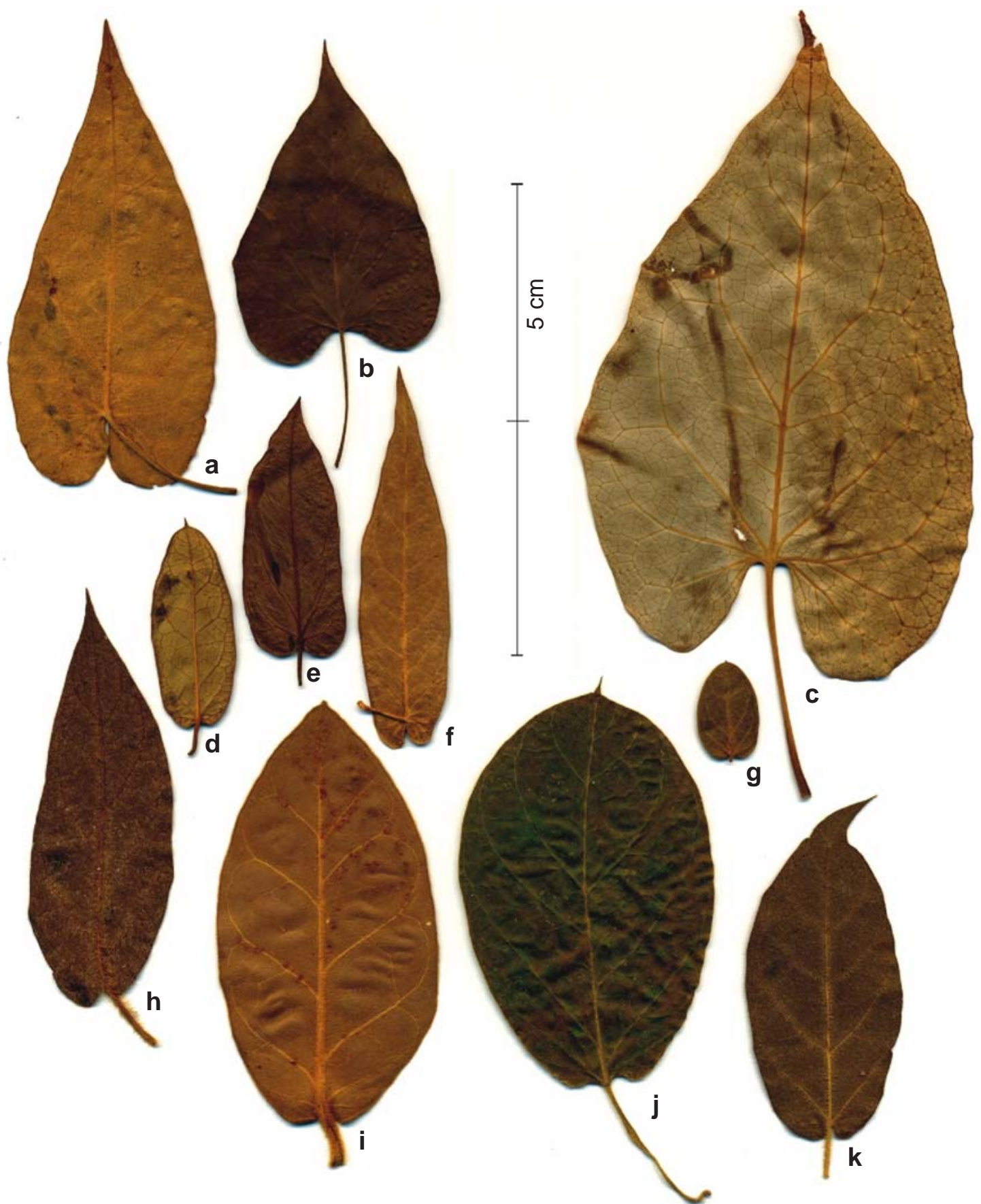

Figura 2 - Variação na forma da lâmina foliar. a. Oxypetalum regnellii-ovado-triangular e base cordada (Brade 16777); b. O. cordifolium subsp. brasiliense - cordiforme, base cordada(Sucre 2724); c. O. cordifolium subsp.pedicellatum-ovada, base auriculada (Bovini 842); d. O. insigne var. glabrum - oblonga, base subcordada (Lombardi 1023); e. O. insigne var. glaziovii - ovado-lanceolada, base subcordada (Marquete 450); f. O. alpinum var. alpinum - lanceolada, base cordada (Pereira 37); g. O. patulum - elíptica, base subcordada (Marquete 340a); h. O. schottii-sublanceolada, base cordada (Góes 788 ); i. O. insigne var. insigne - elíptica, base cordada (Brade 14551); j. O. jacobinae - ovado-oblonga, base subcordada (Bianchini 462); k. O. molle - oval-lanceolada, base subcordada (Marquete 285). 


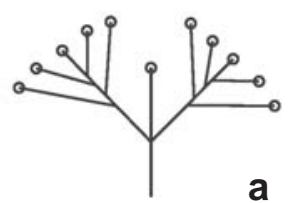

dicásio siadióides corimbiforme

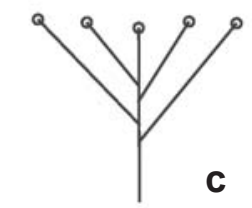

cimóide corimbiforme

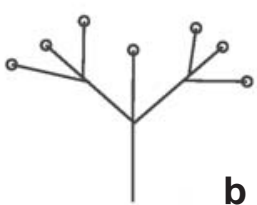

dicásio siadióides umbeliforme

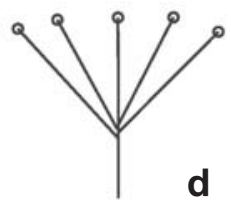

siadióide
Figura 3 - Esquemas dos tipos de inflorescência em espécies de Oxypetalum.

além de raros estômatos situados no mesmo nível das demais células epidérmicas. $\mathrm{O}$ mesofilo apresenta células parênquimáticas heterodimensionais de paredes delgadas, apresentando-se mais compactadas logo abaixo da epiderme, enquanto na parte mediana aparecem alguns espaços intercelulares. Este parênquima é percorrido por 5-6 feixes vasculares colaterais.

As sépalas são geralmente lineares ou lanceoladas, podendo ser também triangulares, ovado-acuminadas ou oblongo-lanceoladas. $\mathrm{Na}$ face adaxial são providas de 1-3 coléteres nas regiões intersepalares, como observado para O. jacobinae e O. cordifolium subsp. brasiliense. Um número maior de coléteres distribuídos por toda a fauce do cálice aparece em $O$. patulum e $O$. cordifolium subsp. pedicellatum. Os coléteres são geralmente cônicos (Fig. 4b-c, e), digitiformes (Fig. 4d, h) ou subcilíndricos (Fig. 4g), e apresentam, às vezes um pedículo de dimensões diminutas $(0,15-0,58$ $\mathrm{mm})$, como observado para $O$. appendiculatum (Fig. 4b), O. insigne var. insigne (Fig. 4c) e O. insigne var. glaziovii (Fig. 4d), e $O$. jacobinae (Fig. 4f). Assim como nas folhas, são constituídos por uma epiderme uniestratificada de células secretoras, dispostas em paliçada e revestidas por uma cutícula delgada.
Internamente encontra-se um parênquima com células de dimensões variáveis, e ausência de vascularização (Fig. 4e).

Tais coléteres são semelhantes aos descritos por Appezato-da-Glória \& Estelita (2000) para Mandevilla illustris e $M$. velutina (Apocynaceae) e por Rio et al. (2002) para Prestonia coalita (Apocynaceae), exceto pela ausência de vascularização, laticíferos e idioblastos taníferos nos coléteres das espécies aqui estudadas. Valente (1977) evidenciou a presença de idioblastos cristalíferos com drusas de oxalato de cálcio e néctar nos coléteres de $O$. banksii subsp. banksii corroborando este estudo.

Os coléteres presentes nas flores de Matelea maritima subsp. ganglinosa são nectaríferos (Valente 1995), como também observado nas espécies aqui estudadas.

A corola é simpétala e pode ser campanulada ou subcampanulada com cinco lacínias (Fig. 5) de cores variadas, predominando as cores rosa, amarelo, esverdeado ou alva. Concavidades na face interna do tubo da corola aparecem em $O$. banksii subsp. banksii e nos táxons subordinados a $O$. insigne, $O$. pannosum var. pannosum, $O$. patulum, $O$. cordifolium subsp. pedicellatum (Fig. 5a) e O. pilosum. Estas concavidades estão situadas entre as sépalas e podem ser observadas externamente, pois se apresentam projetadas radialmente. Segundo Vieira (1998) elas funcionam como reservatório de recurso floral e ampliam o espaço dentro do tubo da corola, desde a sua base, como observado em $O$. cordifolium subsp. pedicellatum.

As lacínias, de prefloração imbricada ou contorta, são comumente lanceoladas, lineares, triangulares, obovadas ou oblongas, planas ou mais freqüentemente, torcidas ou espiraladas. De acordo com sua posição, em relação ao tubo (Tab. 2), podem se apresentar eretas (Fig. $5 b$ ), suberetas, reflexas (Fig. 5c) ou patentes (Fig. 5d).

Podem ser glabras a glabrescentes, ou com o indumento da face adaxial tomentoso ou papiloso na fauce da corola ou na base das 

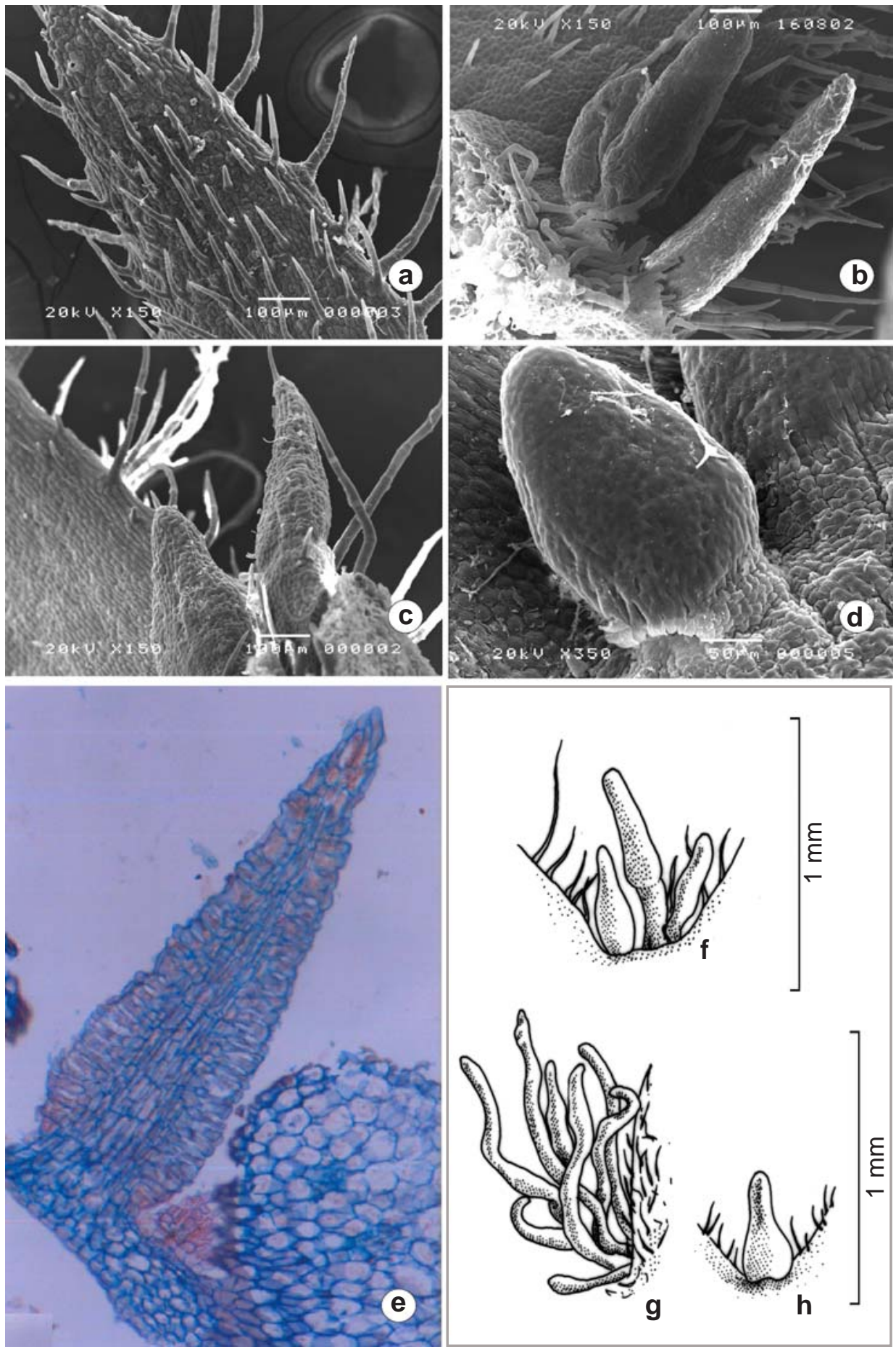

Figura 4-a. O. insigne var. insigne - indumento na face adaxial da sépala (Marquete 369); b-h. coléteres nas sépalas b. O. appendiculatum (Marquete 293); c. O. insigne var. insigne: (Marquete 369); d. O. insigne var. glaziovii (Marquete 450); e. O. insigne var. insigne (Marquete 295); f. O. jacobinae (J.P.Fontella 1023, W.Vidal 362, M.Vidal 392, R.Fortunato \& M.P.Coons); g. O. cordifolium subsp. pedicellatum (Occhioni 5712); h. O. cordifolium subsp. brasiliense (Marquete 447). 


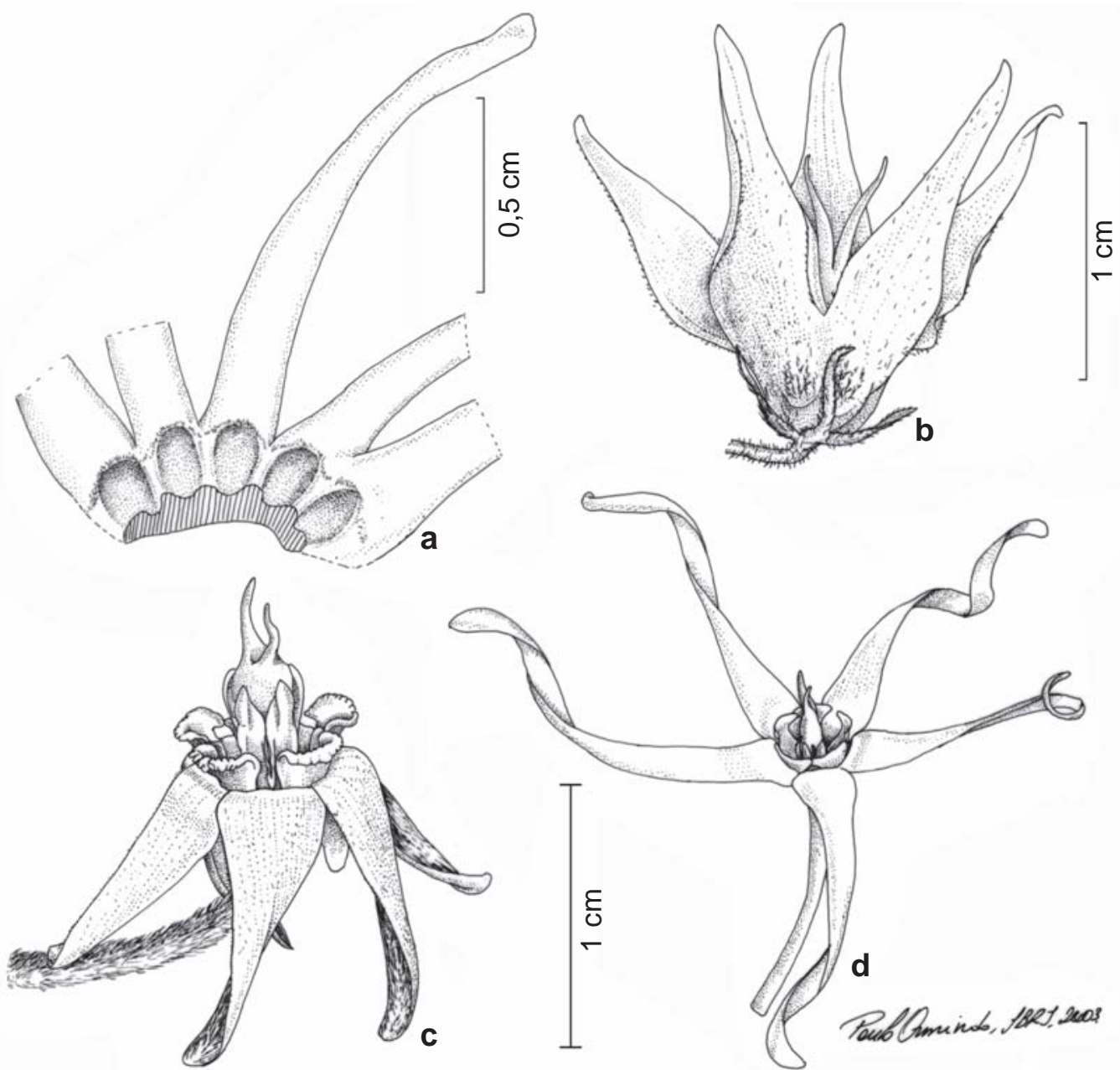

Figura 5 - Aspecto da flor, evidenciando-se a corola. a. Oxypetalum cordifolium subsp. pedicellatum - parte da corola em vista adaxial evidenciando as "bolsas" no tubo; b. O. appendiculatum - lacínias eretas (Marquete 436); c. O. pannosum var. pannosum - lacínias reflexas (Marquete 453); d. O. cordifolium subsp. brasiliense - lacínias patentes (Marquete 447).

lacínias, como observado em $O$. appendiculatum (Fig. 6a) e O. insigne var. insigne (Fig. 6d).

Os tricomas das lacínias do cálice e da corola são simples, unisseriados e pluricelulares, com células de parede lisa ou muricada (Figs. 6b-e, Tab. 2), ou seja, com superfície áspera devido à proeminências curtas e rígidas, segundo Payne (1978).

O tipo da corola, a posição e o tamanho das lacínias em relação ao tubo, bem como a ocorrência e tipo do indumento da face adaxial nos táxons estudados são caracteres de valor taxonômico.

As lacínias da corola em $O$. insigne var. insigne apresentam, na face abaxial, uma epiderme uniestratificada formada por células heterodimensionais, recobertas por cutícula delgada e lisa, e com tricomas pluricelulares. Na face adaxial, a cutícula também se mostra delgada e lisa, e as células epidérmicas são papiliformes, além destas observam-se tricomas uni- e pluricelulares. No mesofilo o parênquima é constituído por células heterodimensionais de paredes delgadas com amplos espaços intercelulares. Imersos nesse parênquima, são observados de 13 a 15 feixes vasculares colaterais.

A corona está situada entre o tubo da corola e o tubo estaminal, apresentando cinco segmentos, com ou sem ornamentações, que 


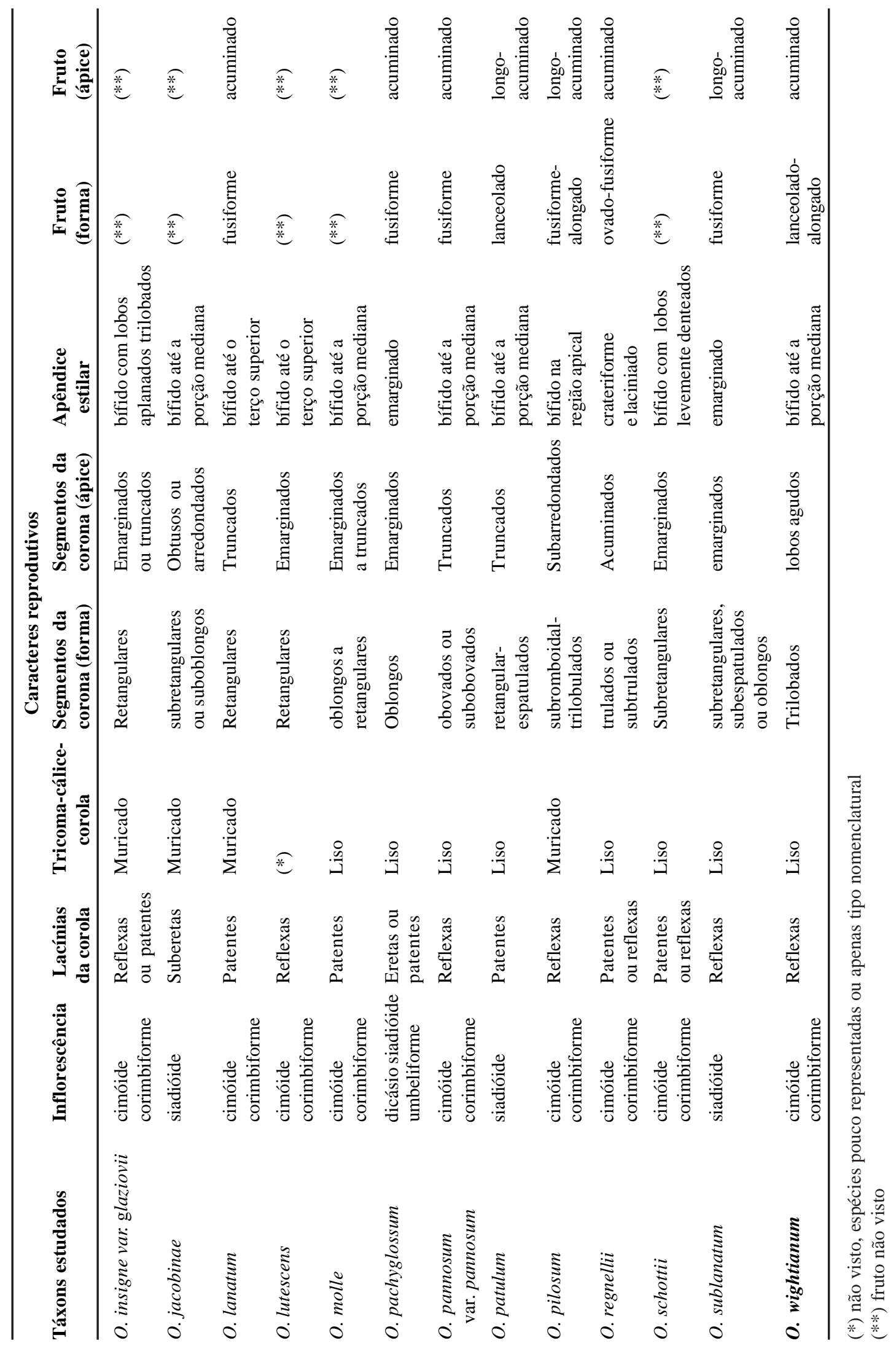



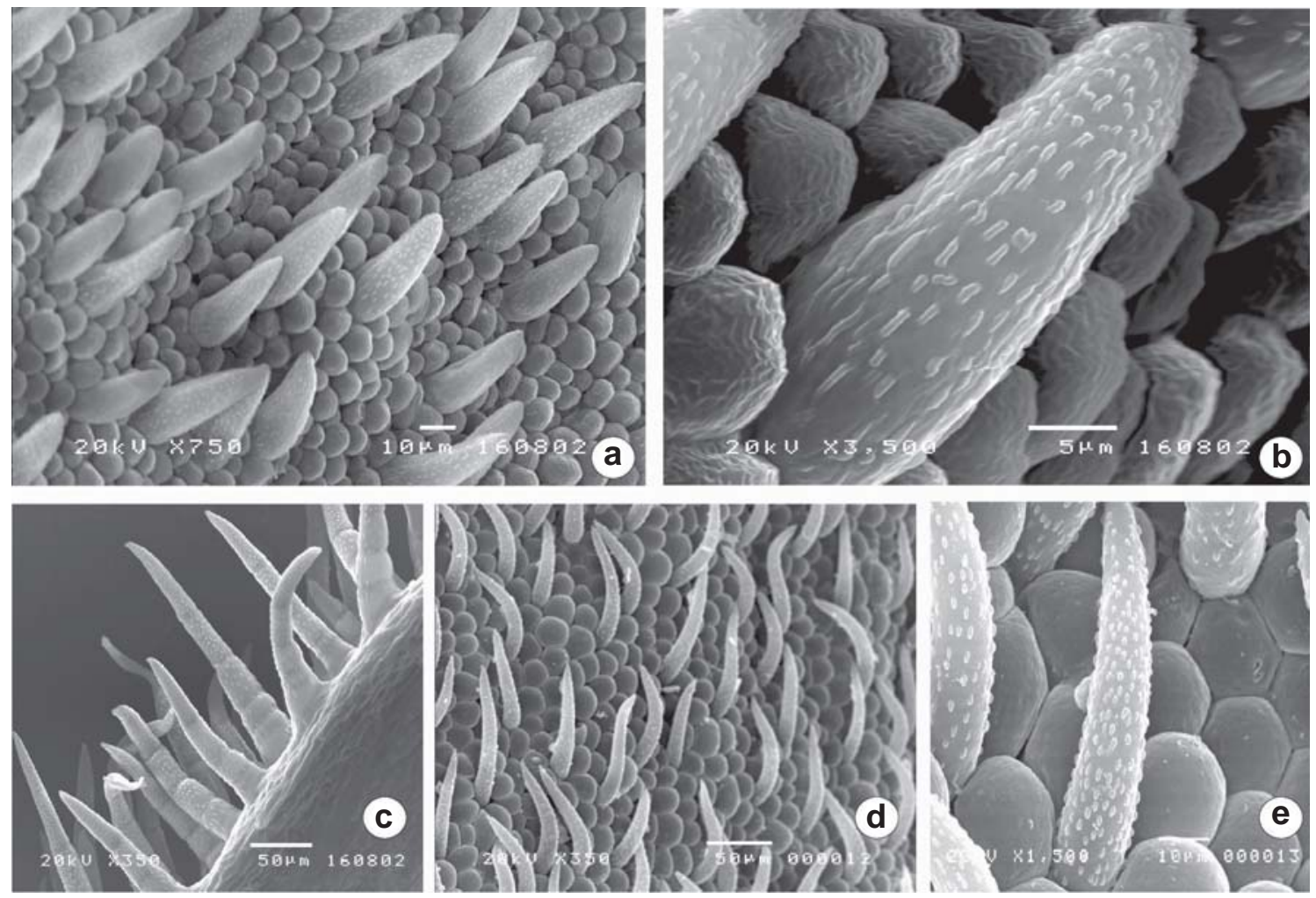

Figura 6 - a-c. Oxypetalum appendiculatum: a. indumento da face adaxial das lacínias; b. detalhe do tricoma com parede muricada; c. tricoma no bordo das lacínias (Marquete 293). d-e. O. insigne var. insigne: d. indumento da face abaxial das lacínias; e. detalhe do tricoma com parede muricada (Marquete 369).

podem estar total ou parcialmente exsertos em relação ao tubo da corola. Os segmentos podem ser livres ou curtamente soldados na base e, são inseridos no tubo da corola e no tubo estaminal (Fig. 7a). Em um nível mais acima, evidencia-se os segmentos da corona ainda presos ao tubo estaminal, porém livres em relação à corola (Fig. 7b). No nível das anteras, os segmentos encontram-se completamente individualizados (Fig. 7c).

Em O. insigne var. insigne a corona é revestida por células epidérmicas retangulares e recoberta por uma camada cuticular delgada. O mesofilo, que apresenta lacunas, possui várias camadas de células parenquimáticas (Fig. 7a-c).

A coloração da corona varia, porém, geralmente é a mesma da corola.

Dois padrões de inserção das coronas foram observados nas espécies estudadas: (1) corona abaxialmente unida à base do tubo da corola e adaxialmente ao dorso da antera. Neste caso, a inserção na corola pode estar concrescida desde a base até próximo a fauce ou até a porção mediana em $O$. alpinum var. alpinum, O. costae, O. glaziovii, O. jacobinae, O. molle, O. schottii, ou simplesmente na base da corola em $O$. appendiculatum, $O$. arachnoideum, $O$. banksii subsp. banksii, $O$. lanatum, $O$. pannosum var. pannosum, $O$. cordifolium subsp. pedicellatum, $O$. regnellii e O. wightianum; (2) corona abaxialmente unida ao tubo da corola e adaxialmente no tubo estaminal em O. glaziovianum, O. insigne var. insigne, $O$. patulum, $O$. sublanatum e $O$. cordifolium subsp. brasiliense. No segundo caso, a corona pode também concrescer com o tubo da corola em $O$. pachyglossum.

Os segmentos da corona variam morfologicamente (Fig. 8a-y), tornando estas estruturas úteis na diagnose em nível específico. Podem ser: 1) providas de dente 

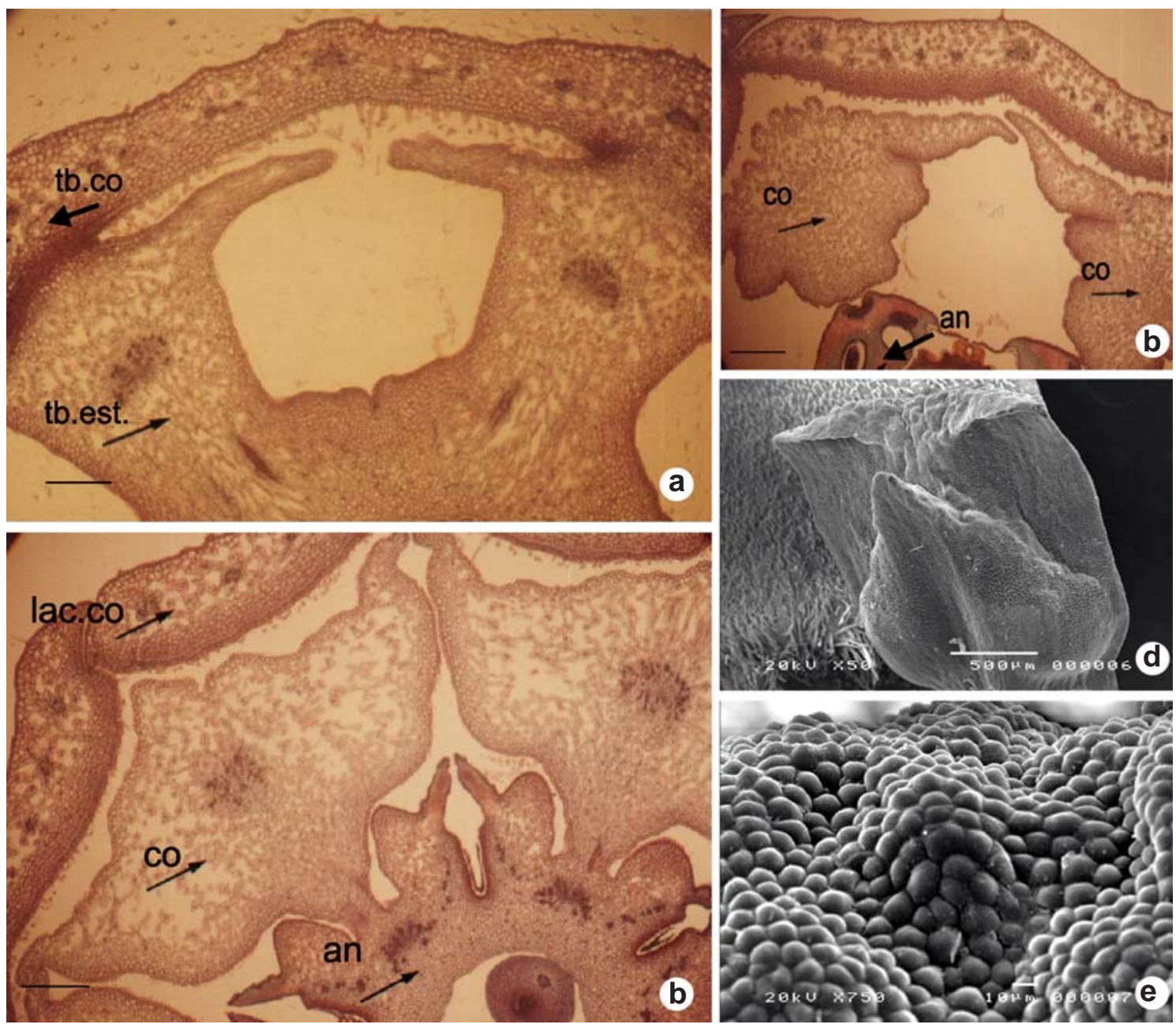

Figura 7 - a-c. Oxypetalum insigne var. insigne - a. segmentos da corona presos externamente ao tubo da corola e internamente ao tubo estaminal; b. em nível mais acima, evidenciamos os segmentos da corola ainda presos ao tubo estaminal e as lacínias da corola já individualizadas; c. segmentos da corona completamente individualizados, em nível das anteras (Marquete 295); d-e. O. insigne var. glaziovii - d. face adaxial ou interna do segmento da corona evidenciando o ápice verrucoso; e. detalhe do ápice verrucoso do segmento da corona em vista frontal (Marquete 450). tb.co = tubo da corola; tb.est. $=$ tubo estaminal; $\mathrm{co}=$ corona; $\mathrm{na}=$ antera; lac. cor $=$ lacínia da corola . Barra $=300 \mu \mathrm{m}$.

central ultrapassando ou não o ápice do segmento (O. cordifolium subsp. pedicellatum, $O$. lanatum, $O$. lutescens, $O$. patulum e $O$. regnellii); 2) providas de dente central com pregas ou espessamentos carnosos laterais na base (O. costae, grupo $O$. insigne, $O$. molle, $O$. schottii); 3) providas de um espessamento linear central, às vezes tênue ( $O$. glaziovianum, $O$. jacobinae, O. pachyglossum e $O$. pilosum); 4) providas de um espessamento central carnoso (O. glaziovii, O. pannosum var. pannosum e $O$. wightianum); 5) providas de dois espessamentos laterais levemente carnosos $(O$. cordifolium subsp. brasiliense); 6) destituídas de dente ou espessamentos (O. alpinum var. alpinum, $O$. appendiculatum, $O$. arachnoideum, $O$. banksii subsp. banksii, $O$. banksii subsp. corymbiferum e O. sublanatum).

A forma e o tipo de ápice dos segmentos da corona também variam (Figs. 7d-e, 8) e (Tab. 2).

A presença de corona caracteriza a subfamília Asclepiadoideae e algumas Apocynoideae. Em Asclepiadoideae, originase pela fusão congênita das pétalas com os estames (Endress 1994). 

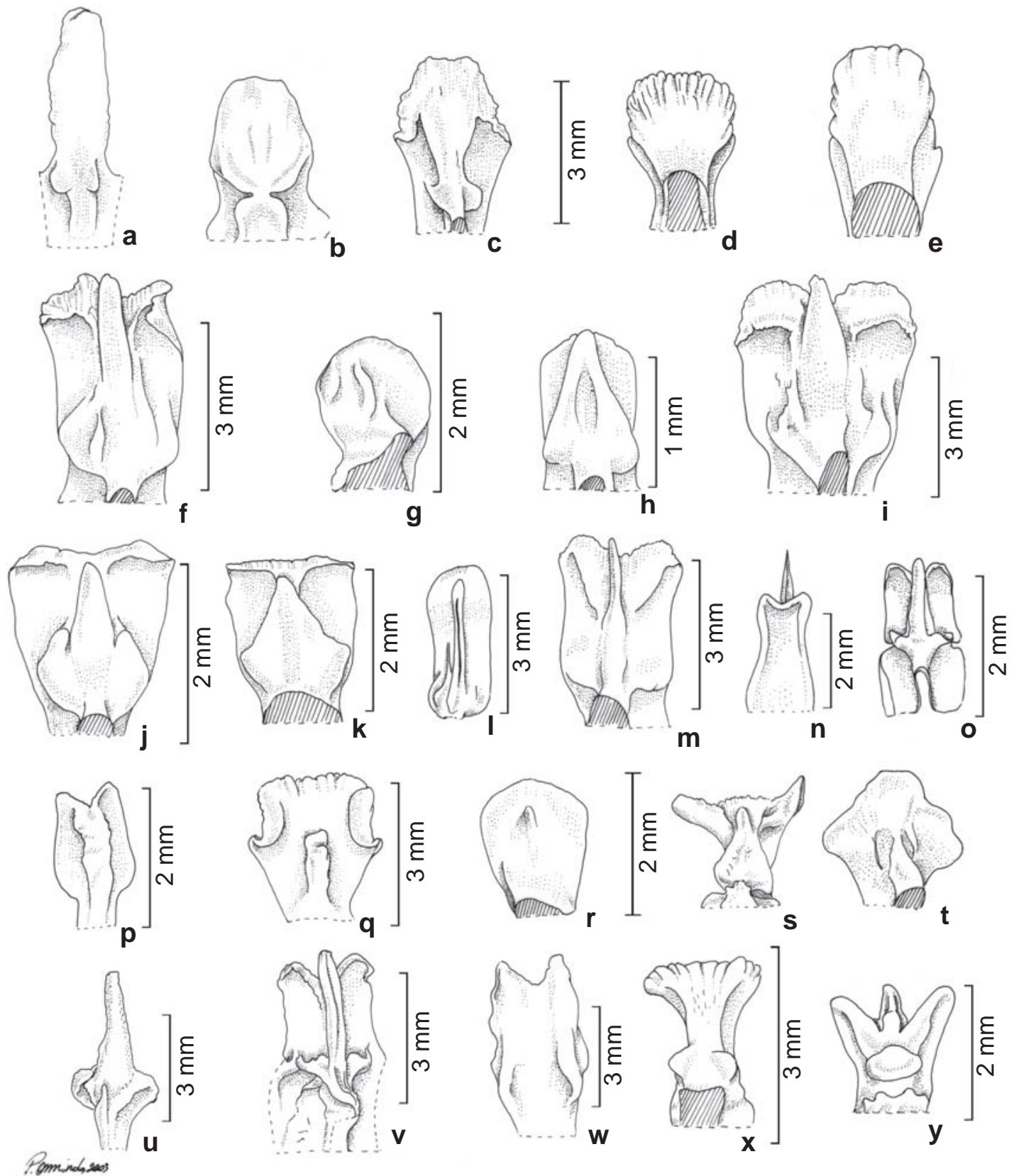

Figura 8 - Variação morfológica dos segmentos da corona, em face adaxial. a. Oxypetalum alpinum var. alpinum (Sucre 6505); b. O. appendiculatum (Marquete 436); c. O. arachnoideum (Duarte 4774); d. O. banksii subsp. banksii (Marquete 323); e. O. banksii subsp. corymbiferum (Marquete 322); f. O. costae (Braga 1570); g. O. glaziovianum (Brade 9839); h. O. glaziovii (Marquete 451); i. O. insigne var. insigne (Brade 17472); j. O. insigne var. glabrum (Rapini 317); k. O. insigne var. glaziovii (Marquete 450); 1. O. jacobinae (Fontella 1023, Vidal 362, Vidal 392); m. O. lanatum (Martinelli 13251); n. face abaxial do segmento da corona evidenciando a porção apical do dente em O. lutescens (Glaziou 6903 ); о. O. molle (Marquete 285); p. O. pachyglossum (Pereira 2938); q. O. pannosum var. pannosum (Marquete 453); r. O. patulum (Brade 20198); s. O. cordifolium subsp. pedicellatum (Occhioni 5712); t. O. pilosum (Sucre 1467); u. O. regnellii (Rizzini 10196); v. O. schottii (Goes 788); w. O. sublanatum (Brade 17272); x. O. cordifolium subsp. brasiliense (Marquete 477); y. O. wightianum (Marquete 452). 
Os segmentos da corona estão unidos ao tubo da corola e ao tubo estaminal e entre si, na região interestaminal, segundo Vieira (1998). Com base no conceito de Liede \& Kunze (1993), de Vieira (1998) e, principalmente, de Valente (1977) a corona é de origem mista, ou seja, corolina e estaminal (Fig. 7a-b), nas espécies estudadas, visto que ocorre fusão dos segmentos da corona com a corola e estão dorsalmente presos no estame.

A morfologia da corona pode ser útil na delimitação dos táxons de Oxypetalum especialmente quanto à sua dimensão, forma e local de inserção.

Segundo Kunze (1991) e Vieira (1998), a corona encontra-se, geralmente, associada ao armazenamento de néctar e à orientação dos insetos polinizadores, servindo também de apoio para o pouso dos insetos e para orientálos sobre a inserção dos polinários.

$\mathrm{O}$ androceu é formado por cinco estames, alternos às lacínias da corola, como nos demais gêneros de Asclepiadoideae (Kunze 1996; Liede 1996; Vieira 1998). Cada estame é constituído de antera, apêndice membranáceo e, em algumas espécies, filete (Fig. 9a).

Os filetes são curtos e unidos formando um tubo que pode estar ausente em $O$. appendiculatum, O. banksii subsp banksii e subsp. corymbiferum, e no grupo $O$.insigne. As anteras são livres entre si, mas apresentamse soldadas à cabeça estilar por sua face superior adaxial até a base dos lóculos (Fig. 12d).

As anteras são bitecas, biesporangiadas, com uma polínia pêndula em cada lóculo (Fig. 9b). Em O. insigne var. insigne, a epiderme das anteras é formada, freqüientemente, por células papiliformes, na face adaxial. No dorso, a superfície é levemente reentrante, na proximidade do feixe vascular. Cada lóculo da antera é revestido por uma camada única de células, de forma e tamanho variável com paredes delgadas (Fig. 9c).

Examinando-se as anteras em botões florais, verificamos que a extremidade lateral de cada uma, forma um bordo saliente que constitui as "asas das anteras" (apêndices estéreis laterais). A secção de cada asa (Fig. 9d) é aproximadamente triangular. A epiderme das asas é uniestratificada e suas células são retangulares e revestidas por uma cutícula delgada e lisa. Sob a epiderme, notam-se várias camadas de células parenquimáticas.

As asas de duas anteras adjacentes formam uma fenda anteral (Fig. 9e) que dá acesso às câmaras nectaríferas (Valente 1977) ou câmara estigmatífera (Galil \& Zeroni 1969; Vieira 1998). As câmaras nectaríferas são revestidas por tecido secretor e produzem néctar (Valente 1977).

$\mathrm{Na}$ porção superior das anteras observam-se apêndices membranáceos (Fig. 9a, f-g), revestidos por epiderme uniestratificada, de células heterodimensionais e recobertas por cutícula delgada e lisa. Internamente, o parênquima é compacto e formado por células heterodimensionais, com paredes delgadas. $\mathrm{O}$ apêndice membranáceo ou membrana apical é um prolongamento do conectivo no ápice da antera e é constituído de uma membrana hialina, inflexa acima da cabeça estilar. Nos representantes da Tribo Asclepiadeae como Oxypetalum, essa estrutura é separada da parte locular da antera por uma contração (Fig. 9a), denominada fenda transversal por Kunze (1996).

O polinário é uma estrutura altamente especializada, e diretamente relacionada à polinização das Asclepiadoideae. Cada polinário (Fig. 10a-k, 11a-k) é formado por uma parte superior, o retináculo, e por duas polínias situadas lateralmente, ao qual se ligam pelas caudículas (Fig. 10a). O translador (retináculo e caudículas) está estreitamente associado ao transporte das polínias pelo polinizador de uma flor para outra. O polinário é de origem heterogênea, ou seja, o translador é secretado na cabeça estilar (Fig. 12a), entre as partes superiores das anteras, acima das fendas anterais. Deste modo, a união entre as anteras e a cabeça estilar, pela fusão posgênita, é necessária para a formação do polinário. As polínias são formadas nos lóculos das anteras. 

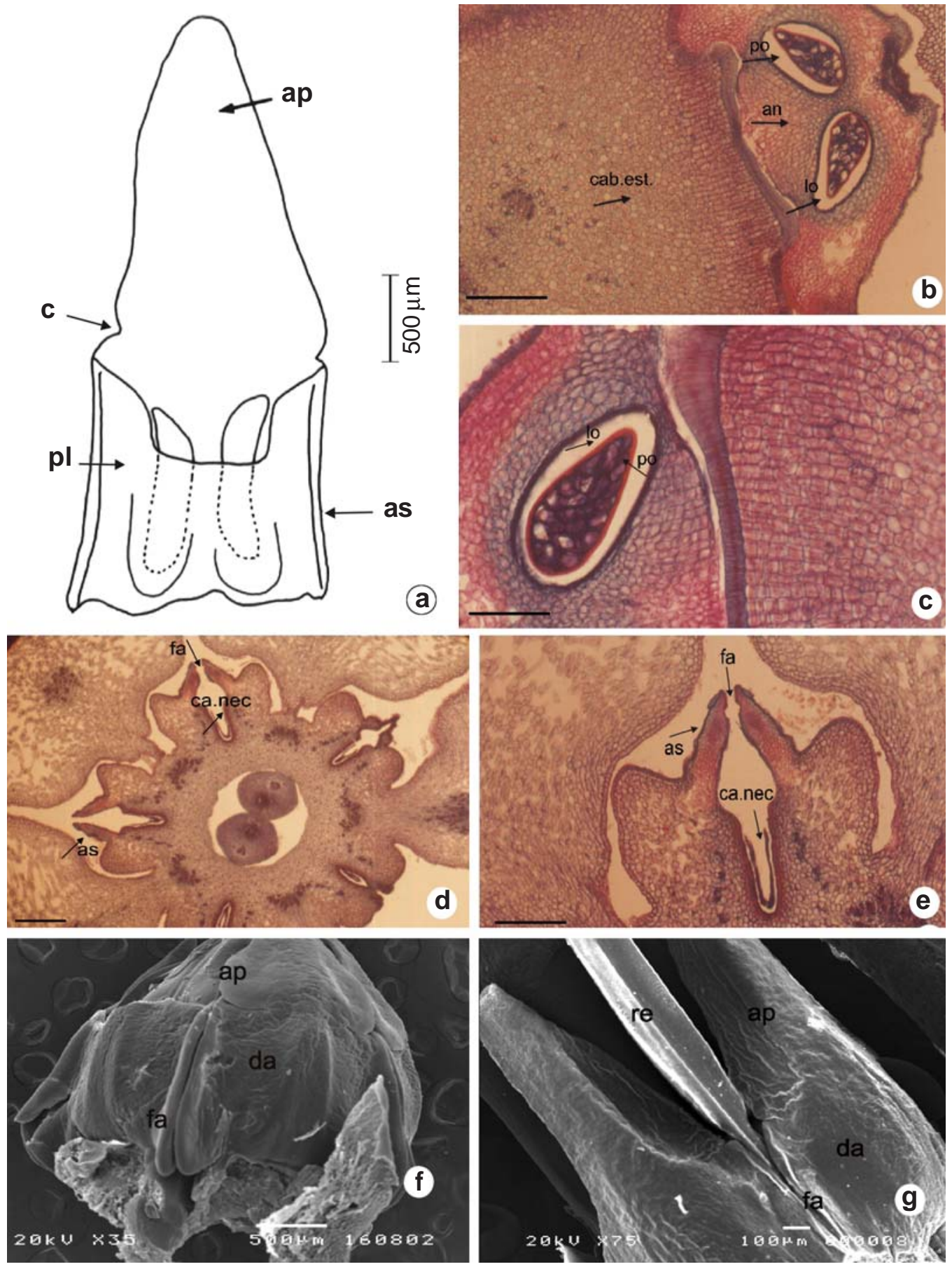

Figura 9 - a-f. Oxypetalum appendiculatum - a. esquema das partes de uma antera; b. aspecto do dorso da antera, evidenciando o achatamento de sua superfície e uma polínia em cada lóculo; c. detalhe do lóculo e da polínia; d. asas das anteras, fendas anterais e câmaras nectaríferas; e. detalhe das asas de anteras adjacentes; f. parte do ginostégio evidenciando as anteras (Marquete 293); g. O. insigne var. glaziovii - detalhe da antera evidenciando o dorso, apêndice membranáceo, fenda anteral e parte do retináculo (Marquete 450). ap=apêndice membranáceo, as=asa da antera; po=polínia; an=antera; cab.est.=cabeça estilar; lo=lóculo da antera; $\mathrm{da}=\mathrm{dorso} ; \mathrm{fa}=$ fenda anteral; ca.nec.=câmara nectarífera; re=parte do retináculo; $\mathrm{c}=$ contração; pl=parte locular. (Escala: $\mathrm{b}-\mathrm{e}=30 \mu \mathrm{m})$ 
O retináculo derivado da secreção da cabeça estilar é composto inicialmente de uma substância semifluída, depois sólida, compacta, tornando-se córnea (Valente 1977, 1995) de cor avermelhada brilhante ou marron-escura, com um sulco ao longo de sua extensão na região mediana (Fig. 12a), que tem por função aprisionar as patas do inseto polinizador, facilitando o transporte do polinário. As patas ou o aparelho bucal dos insetos prendem-se nestes sulcos e carregam os retináculos com suas caudículas e polínias para outra flor. A forma e tamanho dos retináculos são importantes na taxonomia do gênero (Figs. 10-11).

O retináculo é constituído por superposição de placas (Fig. 12b) o que, em secção transversal, dá uma aparência estriada, indicando sua origem a partir de deposições sucessivas da substância secretada pela cabeça estilar (Fig. 12b).
As caudículas são também formadas pela secreção da cabeça estilar, à semelhança dos retináculos. Esta substância é semifluida a princípio, depois se torna parcialmente endurecida e por fim, sólida, dando origem a uma lâmina que se amolda ao formato das células, para constituir as caudículas. Estas se apresentam sob a forma de cunha, cuja cor é amarela ou castanha e, em fase posterior, vão se conectar ao retináculo, originado pelas placas produzidas na região central ficando assim constituído o translador. As caudículas são estruturas semelhantes a braços ou hastes, formadas por uma membrana hialina, que quase sempre é expandida, com nítido espessamento cutinizado, podendo ser também estreita, possuindo um espessamento córneo, dente incluso ou exserto, de cor escura, que caracteriza o gênero (Fig. 12a). As caudículas podem ser horizontais, subhorizontais ou

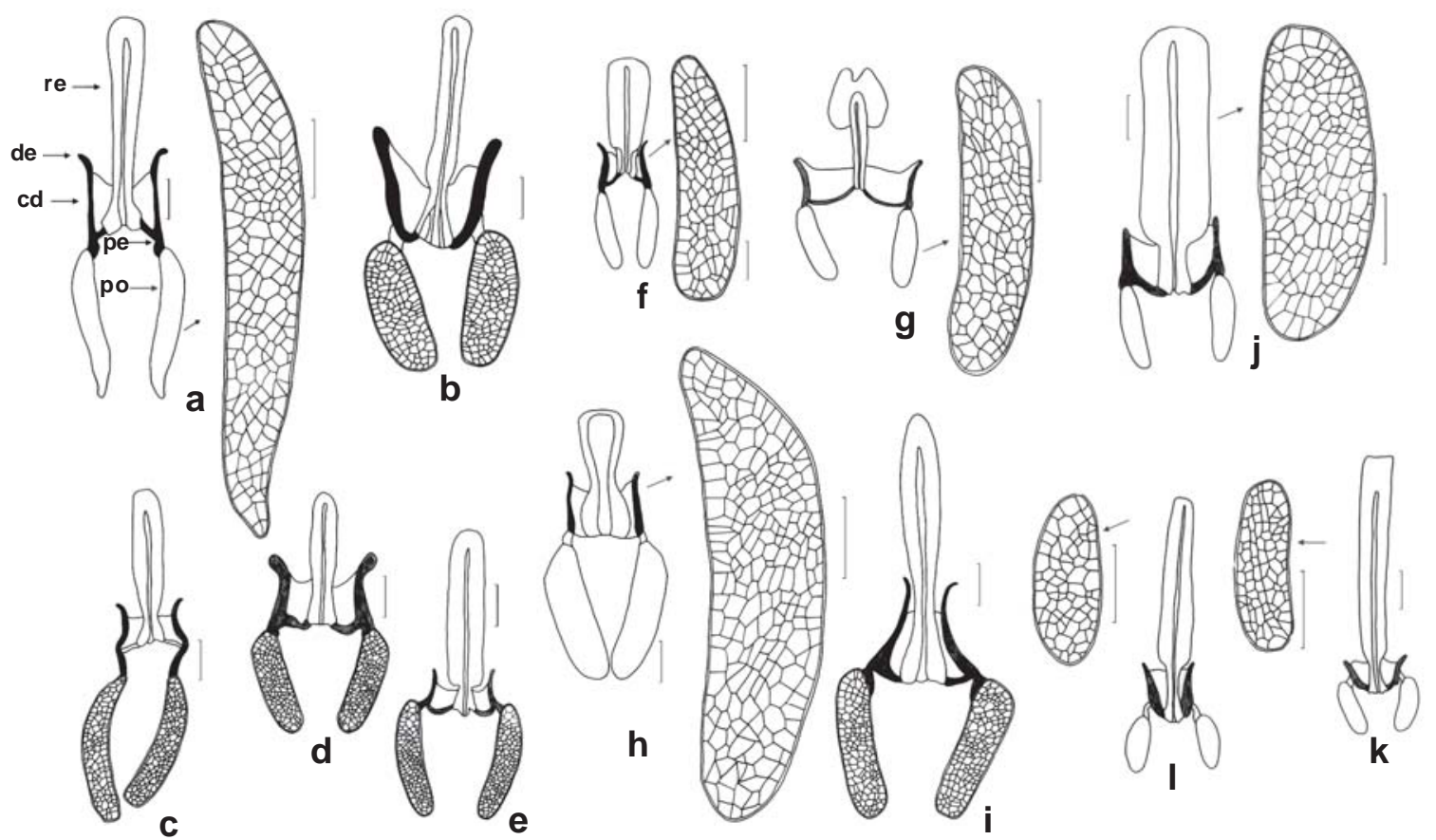

Figura 10 - Polinários - a. Oxypetalum banksii subsp. banksii (Marquete 415); b. O. arachnoideum (Duarte 4774); c. O. cordifolium subsp. brasiliense (Marquete 447); d. O. pilosum (Pereira 26); e. O. cordifolium subsp. pedicellatum (Nadruz 473); f. O. jacobinae (Fontella 1023, Vidal 362, Vidal 392); g. O. appendiculatum (Sucre 4205); h. O. pannosum var. pannosum (Marquete 453); i. O. regnellii (Costa 503); j. O. insigne var. insigne (Klein 666); k. O. insigne var.

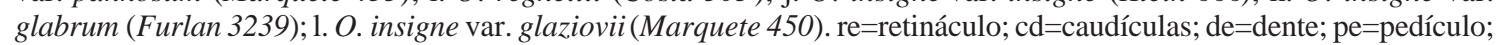
po=polínia. Barra $=200 \mu \mathrm{m}$ 

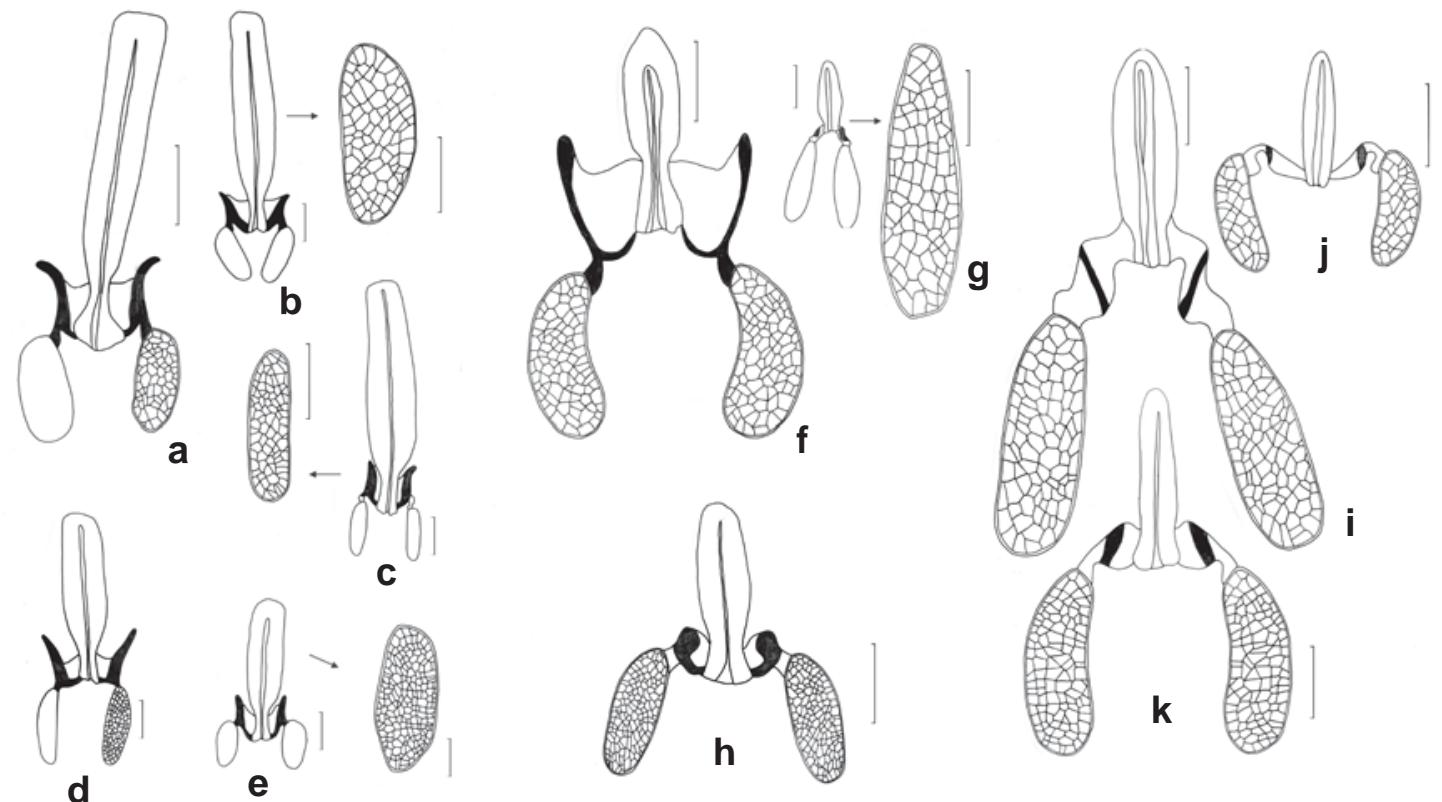

Figura 11 - Polinários - a. Oxypetalum glaziovianum (Brade 9839); b. O. molle (Marquete 285); c. O. schottii (Góes 623); d. O. lanatum (Martinelli 13251); e. O. sublanatum (Brade 17272); f. O. wightianum (Marquete 452); g. O.pachyglossum (Pereira 2938); h. O. costae (Braga 1570); i. O. alpinum var. alpinum (Sucre 6505); j. O. glaziovii (Marquete 451); k. O. patulum (Brade 20198). Barra $=200 \mu \mathrm{m}$
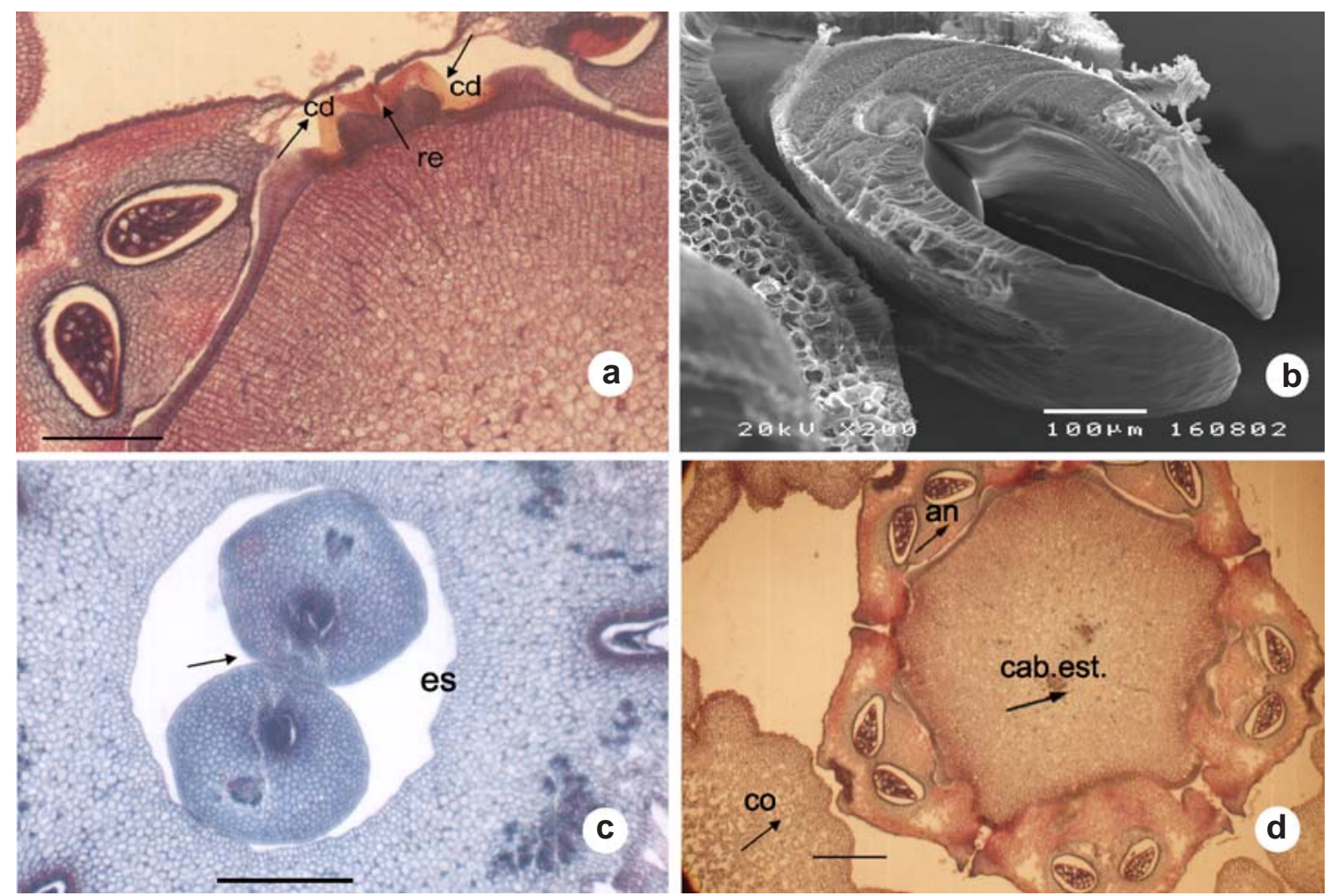

Figura 12 - Oxypetalum appendiculatum - a. detalhe da formação do retináculo e caudículas. b. corte do retináculo e sua formação em placas; c. união dos estiletes. d. anteras livres entre si, e presas pela sua face superior à cabeça estilar (Marquete 293). es=estilete; cab.est. $=$ cabeça estilar; $c 0=$ corona; na=antera; re=retináculo; cd=caudículas. Barra $=200 \mu \mathrm{m} ; \mathrm{Barra}=300 \mu \mathrm{m}$ 
Tabela 3 -Distribuição das características das polínias, caudículas e retináculos de 24 táxons de Oxypetalum.

\begin{tabular}{|c|c|c|c|c|c|c|c|c|c|c|c|}
\hline TÁXONS & $\mathbf{a}$ & b & c & d & e & f & g & $\mathbf{h}$ & $\mathbf{i}$ & $\mathbf{j}$ & $\mathbf{k}$ \\
\hline O. alpinum var. alpinum & 0,35 & 0,11 & 0,52 & 0,17 & 1 & 1 & 1 & + & + & - & - \\
\hline O. appendiculatum & 0,88 & 0,11 & 0,61 & 0,15 & 2 & 2 & 1 & - & + & + & + \\
\hline O. arachnoideum & 1,58 & 0,14 & 0,81 & 0,20 & 2 & 2 & 1 & - & + & - & + \\
\hline O. banksii subsp. Banskii & 1,65 & 0,28 & 1,23 & 0,20 & 2 & 3 & 2 & - & + & - & + \\
\hline O. cordifolium subsp. Brasiliense & 0,75 & 0,13 & 0,67 & 0,12 & 2 & 2 & 4 & + & + & - & + \\
\hline O. cordifolium subsp. Pedicellatum & 0,88 & 0,17 & 0,54 & 0,11 & 2 & 2 & 4 & + & + & - & + \\
\hline O. costae & 0,75 & 0,29 & 0,64 & 0,23 & 2 & 4 & 3 & + & + & - & - \\
\hline O. glaziovianum & 2,77 & 0,40 & 0,74 & 0,32 & 2 & 2 & $1 / 3$ & + & + & - & + \\
\hline O. glaziovii & 0,27 & 0,07 & 0,27 & 0,08 & 2 & 2 & $1 / 5$ & + & + & - & - \\
\hline O. insigne var. insigne & 1,84 & 0,35 & 0,66 & 0,17 & 2 & 1 & 1 & + & + & - & + \\
\hline O. insigne var glabrum & 1,69 & 0,22 & 0,39 & 0,11 & 2 & 1 & 1 & + & + & - & + \\
\hline O. insigne var. glaziovii & 1,23 & 0,20 & 0,37 & 0,14 & 2 & 1 & $1 / 3$ & + & + & - & + \\
\hline O. jacobinae & 0,62 & 0,26 & 0,49 & 0,14 & 3 & 1 & 1 & + & + & - & + \\
\hline O. lanatum & 1,15 & 0,32 & 0,52 & 0,16 & 2 & 2 & 1 & + & + & - & + \\
\hline O. lutescens & 0,61 & 0,10 & 0,62 & 0,24 & 2 & 2 & 4 & + & + & - & + \\
\hline O. molle & 1,29 & 0,35 & 0,48 & 0,15 & 2 & 1 & $1 / 3$ & + & + & - & + \\
\hline O. pachyglossum & 0,56 & 0,17 & 0,66 & 0,21 & 1 & $1 / 5$ & 1 & + & + & - & - \\
\hline O. pannosum var. pannosum & 0,94 & 0,28 & 0,98 & 0,25 & 2 & 6 & 1 & - & - & - & + \\
\hline O. patulum & 0,45 & 0,13 & 0,50 & 0,14 & 3 & 5 & 3 & - & + & - & - \\
\hline O. pilosum & 0,65 & 0,10 & 0,49 & 0,13 & 2 & 1 & 1 & + & - & - & + \\
\hline O. regnellii & 1,20 & 0,22 & 0,65 & 0,17 & 2 & 3 & 1 & - & + & - & + \\
\hline O. schottii & 1,70 & 0,53 & 0,46 & 0,21 & 2 & 1 & $1 / 3$ & + & + & - & + \\
\hline O. sublanatum & 3,07 & 0,79 & 0,78 & 0,34 & 2 & 7 & 1 & + & + & - & + \\
\hline O. wightianum & 0,52 & 0,07 & 0,38 & 0,11 & 2 & 2 & 1 & + & - & - & + \\
\hline
\end{tabular}

Média dos comprimentos e larguras em mm. retináculo - a. comprimento; b. largura; polínias c. comprimento d. largura; e. orientação das caudículas - 1. descendentes; 2 . horizontais; 3 . subhorizontais; f. forma dos retináculos -1 . oblonga e variações; 2. linear, sublinear e linear-oblonga; 3. subclaviforme; 4. obovada; 5. lanceolada; 6. ossiforme; 7. retangular, subretangular; g. forma das polínias - 1. oblonga e variações; 2. sigmóides; 3. subobovada, elíptica; 4. cilíndrica; 5. sublinear, linear-oblonga; h. consistência dos retináculos - (+) fina; (-) espessado; i. inserção da caudícula no retináculo - (-) base até a porção mediana (+) basal ou sub-basal; j. apêndices no retináculo - (-) ausentes (+) presente; k. presença de dente na caudícula - (+) dente livre (-) dente incluso.

pêndulas. A inserção da caudícula no retináculo constitui caráter em nível específico (Tab. 3). Cada uma dessas estruturas sustenta uma polínia em anteras adjacentes (Fig. 12a).

O retináculo, assim como as caudículas, têm superfície brilhante e consistência córnea, mas o retináculo distingue-se das caudículas por sua cor castanho-avermelhada.

A polínia é um aglomerado de grãos de pólen, firmemente unidos em uma massa sólida, envolvida pela ectexina. Cada lóculo de uma antera contém apenas uma polínia (Fig. 9c), que fica pêndula e solta dentro do lóculo, presa a caudícula apenas no seu ápice.

As polínias, sob microscopia óptica, apresentam ectexina fina com reticulado mais ou menos homogêneo de forma pentagonal, hexagonal mais raramente quadrangular, com variações que chegam a formatos mais curvos nas espécies estudadas (Figs. 10-11). Estas variações geralmente ocorrem em uma mesma polínia. De cada polínia projetam-se inúmeros tubos polínicos, frequientemente visíveis na própria preparação utilizada para realização do estudo dos polinários em microscopia ótica.

As polínias nas Asclepiadoideae estão dispostas de três maneiras: pêndulas (Asclepiadeae, Oxypetalum), horizontais (Matelea) e eretas (Marsdenieae, Marsdenia), segundo Schumann (1895). Nos diversos tratamentos sistemáticos, as polínias, caudículas e retináculos são utilizados 
principalmente em nível de tribos (Schumann 1895).

A forma da polínia, assim como seu tamanho em relação ao retináculo, pode ter valor diagnóstico para as espécies estudadas. As polínias podem ser: 1$)$ três vezes menores que o retináculo $(O$. glaziovianum, grupo da espécie $O$. insigne, $O$. lanatum, $O$. molle, $O$. schottii e $O$. sublanatum) ou 2) levemente menores ou maiores, porém nunca três vezes menores que o retináculo $(O$. alpinum var. alpinum, $O$. appendiculatum, $O$. arachnoideum, $O$. banksii subsp. banksii, $O$. banksii subsp. corymbiferum, $O$. costae, $O$. cordifolium subsp. brasiliense, O. cordifolium subsp. pedicellatum, O. glaziovii, $O$. jacobinae, O. pachyglossum, O. pannosum var. pannosum, $O$. patulum, $O$. pilosum, $O$. regnellii e $O$. wightianum). A Tabela 3 apresenta um quadro comparativo de características quali-quantitativas das polínias, em relação aos táxons de Oxypetalum.

A forma, o tamanho e a inserção da caudícula no retináculo e nas polínias bem como a presença de dentes livres ou inclusos são aspectos importantes nas circunscrições de subgêneros e seções de Oxypetalum, segundo Fournier (1885) e Malme (1900a,b; 1927). A importância dos polinários na taxonomia das espécies também foi destacada por Fontella-Pereira (1977), quando da revisão do gênero Tassadia.

O gineceu é constituído por um ovário súpero formado de dois carpelos livres, que se estreitam gradualmente unindo-se ao nível dos estiletes (Fig. 12c), que se expandem para formar a cabeça estilar. Os estames também se fundem com a cabeça estilar, na parte superior da coluna dos filetes (Fig. 12d). Esta soldadura do androceu e do gineceu constitui a estrutura denominada ginostégio, que é cilíndrica, curta ou séssil e que pode estar oculta ou não pelo tubo da corola. A Figura 13(a-c) evidencia o prolongamento do ginostégio que forma o apêndice estilar.

Os dois carpelos são completamente livres no ápice do ovário (Fig. 13d). As paredes dos carpelos são revestidas por uma epiderme uniestratificada. A região mediana da parede dos carpelos apresenta várias camadas de células parenquimáticas diminutas. A placenta (Fig. 13e) é constituída em sua parte interna por um tecido parenquimático com células pequenas. Nos locais de inserção dos óvulos a parede placentária é constituída por uma epiderme que pode ser contínua ou constituir projeções para a fixação dos óvulos formando os funículos (Fig. 13e).

Os carpelos (Fig. 13e) mostram uma placenta marginal (Puri 1952) com numerosos óvulos, anátropos, pseudo-crassinucelados e unitegumentados (Rosatti 1989). Um dos carpelos geralmente aborta na formação do fruto (Vieira 1998).

A cabeça estilar, também denominada de cabeça do ginostégio ou de cabeça estigmática, apresenta um prolongamento apical, crasso, alongado e geralmente bifurcado no ápice, formando o apêndice estilar (Fig. 13a-c). Esta é circundada por tecido secretor que, entre as anteras logo acima das fendas anterais, secreta os transladores (Fig. 12d).

O apêndice estilar (Figs. 14-15), freqüentemente, divide-se em dois lobos ou ramos laciniados no ápice, e constitui também uma característica útil na delimitação de grupos de espécies (Tab. 2).

Vascularização floral: a sépala é vascularizada por três feixes. O mediano percorre as lacínias desde o pedicelo sem ramificações, a não ser no encontro com as duas secundárias, na porção apical, onde geralmente os feixes apresentam maior calibre. Os feixes secundários podem ser ramificados ou não, com ramificações ascendentes e descendentes (Fig. 16a-d).

A vascularização das sépalas apresenta cinco padrões diferentes: (1) os feixes secundários se ligam ao mediano na porção subapical, sendo que este continua seu percurso até o ápice da sépala, com poucas ou nenhuma ramificação (O. insigne var. glabrum - Fig. 16a, O. jacobinae e O. patulum); (2) os feixes secundários unem-se ao mediano na porção apical, e nenhum feixe apresenta ramificação (O. insigne var. glaziovii e $O$. 


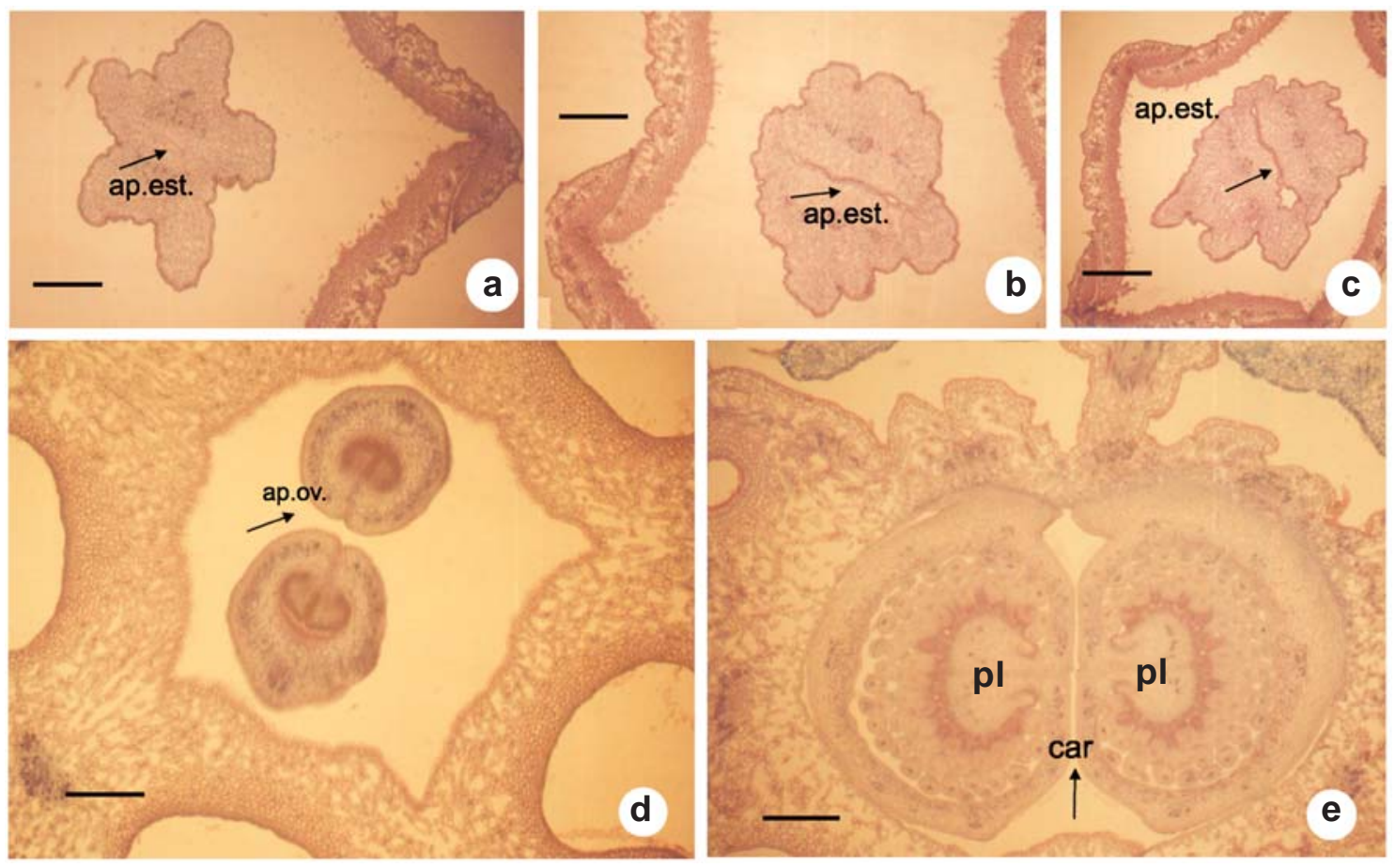

Figura 13 - a-c. prolongamento da cabeça estilar para formar o apêndice estilar, evidenciando o início da bifurcação dos ramos; d. ápice do ovário; e. carpelos livres. car=carpelos; ap.ov.=ápice do ovário; ap.est.=apêndice estilar; pl=placenta. Barra=300 $\mu \mathrm{m}$

pilosum - Fig. 16b); (3) os feixes secundários unem-se ao mediano no ápice da sépala $(O$. banksii subsp. banksii, subsp. corymbiferum, O. insigne var. glabrum, O. pachyglossum, $O$. cordifolium subsp. brasiliense e $O$. wightianum) ou na sua porção subapical ( $O$. arachnoideum); o feixe mediano não possui ramificação e os secundários sim em $O$. arachnoideum; (4) os feixes secundários unem-se ao mediano desde a base e se ramificam; nesse caso os feixes são mais espessados ( $O$. alpinum var. alpinum, $O$. appendiculatum, $O$. insigne var. insigne, $O$. cordifolium subsp. pedicellatum (feixes mais tênues e secundários com menos ramificações) e O. regnellii (Fig. 16c); (5) os feixes secundários unem-se ao mediano na porção mediana da sépala e apresentam poucas ramificações (O. glaziovii, $O$. insigne var. glabrum) ou muitas (O. molle (Fig. 16d).

As lacínias da corola são percorridas por três feixes vasculares: um mediano que, na maioria das espécies apresenta poucas ramificações no ápice, e dois secundários que percorrem toda a lacínia, ligando-se ao feixe mediano na sua parte apical. Em $O$. alpinum var. alpinum, $O$. appendiculatum, $O$. arachnoideum, $O$. banksii subsp. banksii e subsp. corymbiferum, $O$. jacobinae, $O$. patulum, O. cordifolium subsp. pedicellatum, $O$. pilosum, $O$. regnellii e $O$. wightianum, o feixe mediano é pouco ou não ramificado e os secundários são muito ramificados com feixes descendentes. Em $O$. insigne var. insigne, $O$. insigne var. glabrum, $O$. insigne var. glaziovii e $O$. cordifolium subsp. brasiliense os feixes secundários são pouco ramificados. Em O. insigne var. glabrum a nervação é mais laxa que nas demais espécies. O bordo da lacínia é pouco ou não ramificado (Fig. 16f). Em $O$. sublanatum, $O$. molle e $O$. lanatum as lacínias também são percorridas por três feixes, mas os bordos apresentam numerosas ramificações vasculares descendentes (Fig. $16 \mathrm{e}, \mathrm{g})$.

Cada estame recebe um feixe vascular, que na maioria das espécies atinge o apêndice membranáceo sem se ramificar (Figs. 17a-d, 

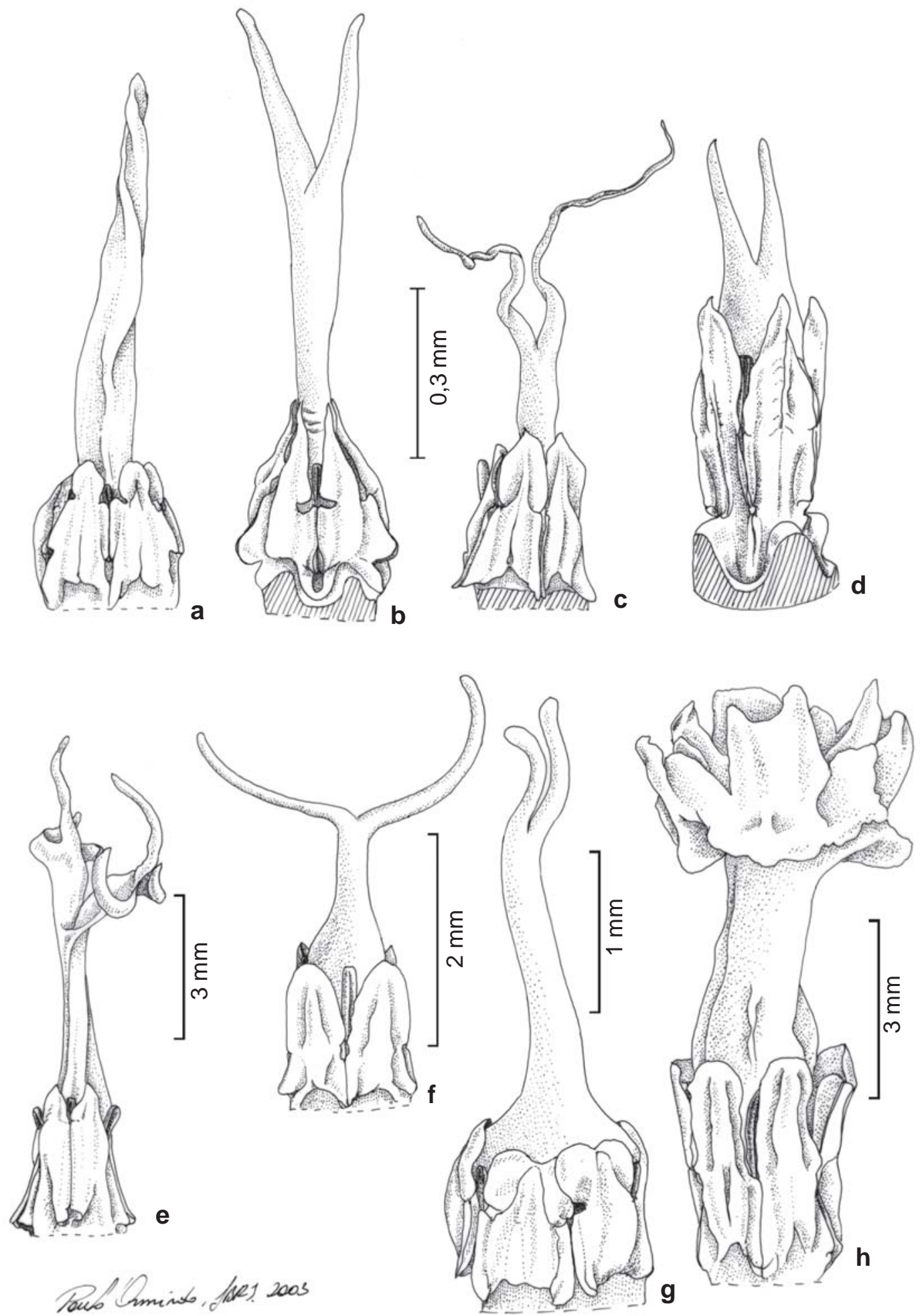

Figura 14 - Variação morfológica dos apêndices estilares - a. Oxypetalum alpinum var. alpinum (Sucre 6505); b. O. appendiculatum (Marquete 436); c. O. arachnoideum (Duarte 4774); d. O. banksii subsp. banksii (Marquete 323); e. O. costae (Braga 1570); f. O. glaziovianum (Brade 9839); g. O. glaziovii (Marquete 451); h. O. insigne var. insigne (Brade 17472). 


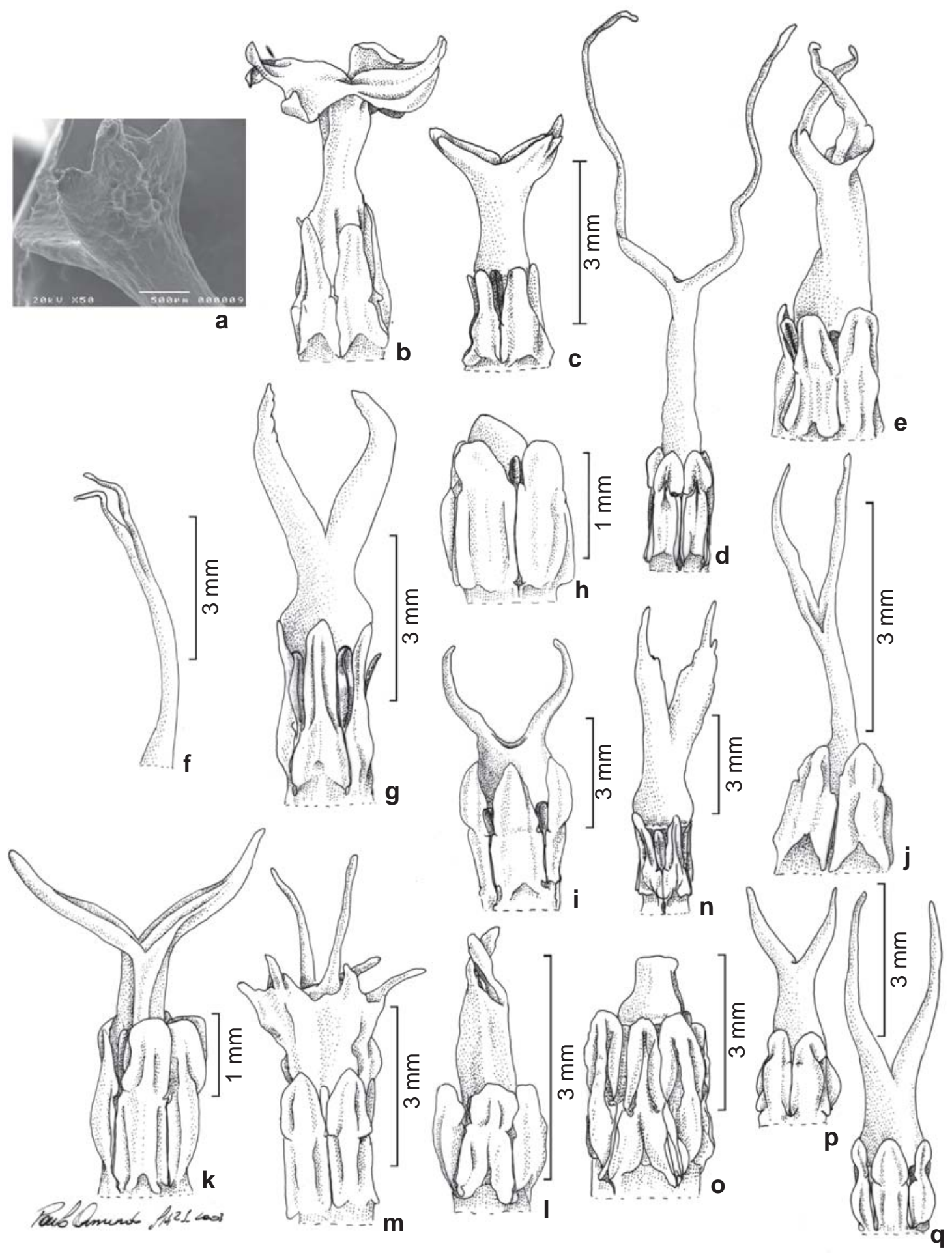

Figura 15 - Variação morfológica dos apêndices estilares - a. Oxypetalum insigne var. glaziovii (Marquete 450); b. O. insigne var. glabrum (Rapini 317); c. O. insigne var. glaziovii (Marquete 450); d. O. jacobinae (Fontella 1023, Vidal 362, Vidal 392); e. O. lanatum (Martinelli 13251); f. O. lutescens (Glaziou 6903); g. O. molle (Marquete 285); h. O. pachyglossum (Pereira 2938); i. O. pannosum var. pannosum (Marquete 453); j. O. patulum (Brade 20198); k. O. cordifolium subsp. pedicellatum (Occhioni 5712); 1. O. pilosum (Sucre 1467); m. O. regnellii (Rizzini 10196); n. O. schottii (Góes 788); o. O. sublanatum (Brade 17272); p. O. cordifolium subsp. brasiliense (Marquete 477); q. O. wightianum (Marquete 452). 

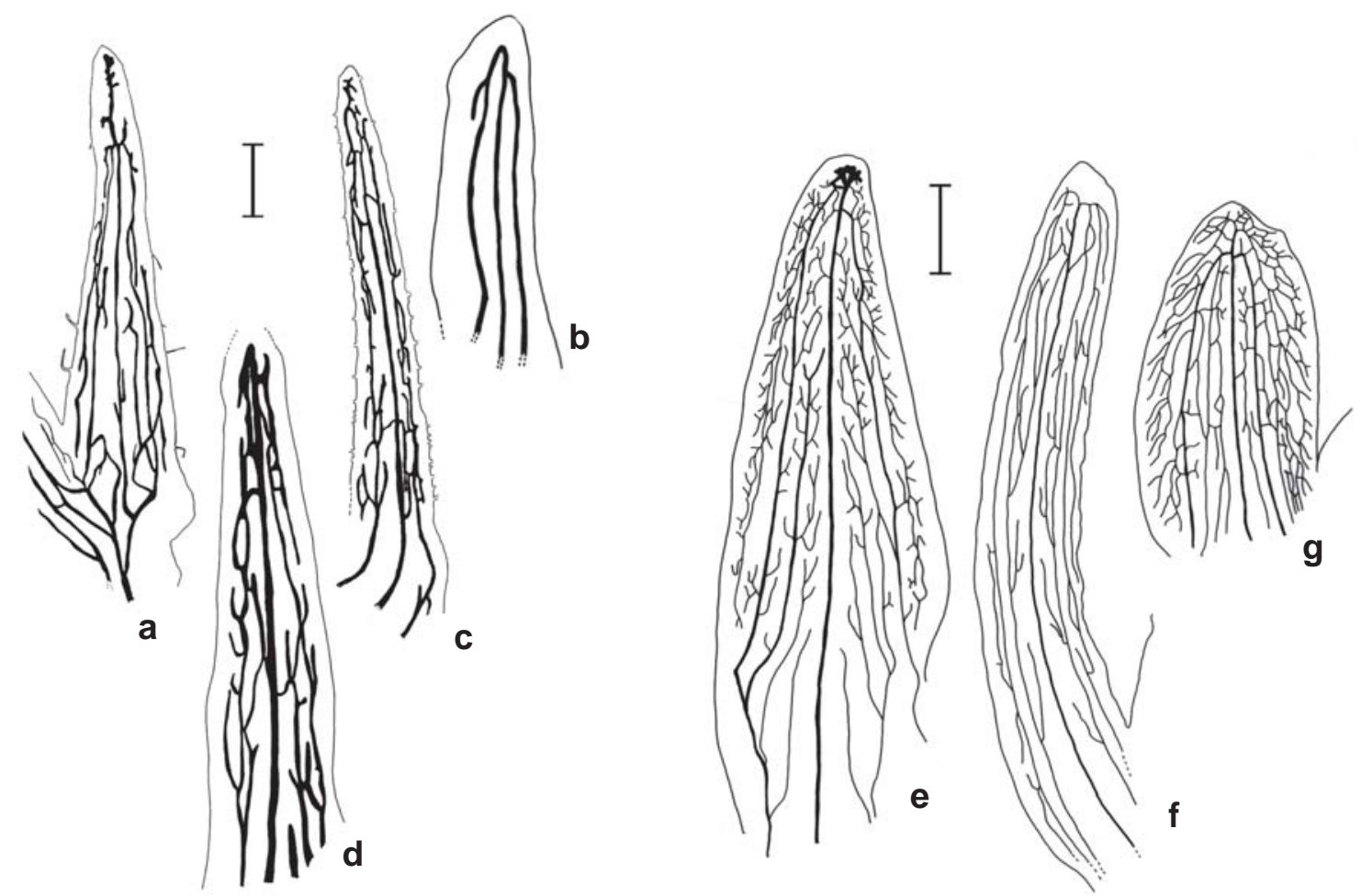

Figura 16 - Vascularização das sépalas. a. Oxypetalum insigne var. glabrum (Furlan 3239); b. O. pilosum (Góes 1201); c. O. regnellii (Occhioni 1285); d. O. molle (Kuhlmann 1969). Vascularização das lacínias da corola. e. O. sublanatum (Lima 1150); f. O. insigne var. glabrum (Furlan 3239); g. O. lanatum (Farney 1428). Barra = 2 mm

$\mathrm{f}-\mathrm{l}, \mathrm{n}-\mathrm{u}$ ); raramente, o feixe se ramifica em dois ou três na porção mediana do apêndice membranáceo como em $O$. banksii subsp. corymbiferum e $O$. pannosum var. pannosum (Fig. 17e, m).

As coronas em geral não são vascularizadas (Fig. 18d, i-k, m, q, s-u), exceto em $O$. arachnoideum (Fig. 18c), O. insigne var. insigne (Fig. 18f), O. insigne var. glabrum (Fig. 18g), O. patulum (Fig. 18n) e O. cordifolium subsp. pedicellatum (Fig. 18o). Nestas últimas espécies, o feixe vascular atinge a base do segmento, sendo que em $O$. patulum este feixe ramifica-se subapicalmente em três. Oxypetalum sublanatum (Fig. 18r) apresenta dois feixes percorrendo o segmento da corona até a região mediana sendo que um deles se ramifica apicalmente. Os feixes às vezes se dirigem aos segmentos da corona, mas não penetram nos mesmos, como em $O$. alpinum var. alpinum (Fig. 18a), O. appendiculatum (Fig. 18b), O. banksii subsp. corymbiferum (Fig. 18e), O. insigne var. glaziovii (Fig. 18h), O. pachyglossum (Fig. 181) e O. pilosum (Fig. 18p).

Cada estilete apresenta um feixe vascular que não se unem na soldadura do ginostégio, e nem atingem o apêndice estilar e seus ramos (Fig. 19a-i, k-s, u). Quando o apêndice estilar possui o ápice crateriforme e laciniado, como em O. insigne var. insigne (Fig. 19j) e $O$. regnellii (Fig. 19t), os feixes ramificam-se, penetrando um em cada lacínia.

Fruto: a forma dos folículos varia de fusiforme a ovóide sendo geralmente acuminados no ápice (Tab. 2). A superfície é frequientemente lisa (Fig. 20c), estriada longitudinalmente (Fig. 20a), ou tuberculada em O. wightianum (Fig. 20d). O indumento varia de glabro a pubescente.

Os folículos quando maduros possuem pericarpo muito delgado, de cor marrom, com 


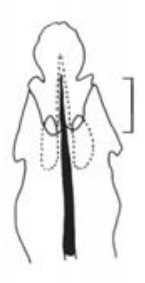

a
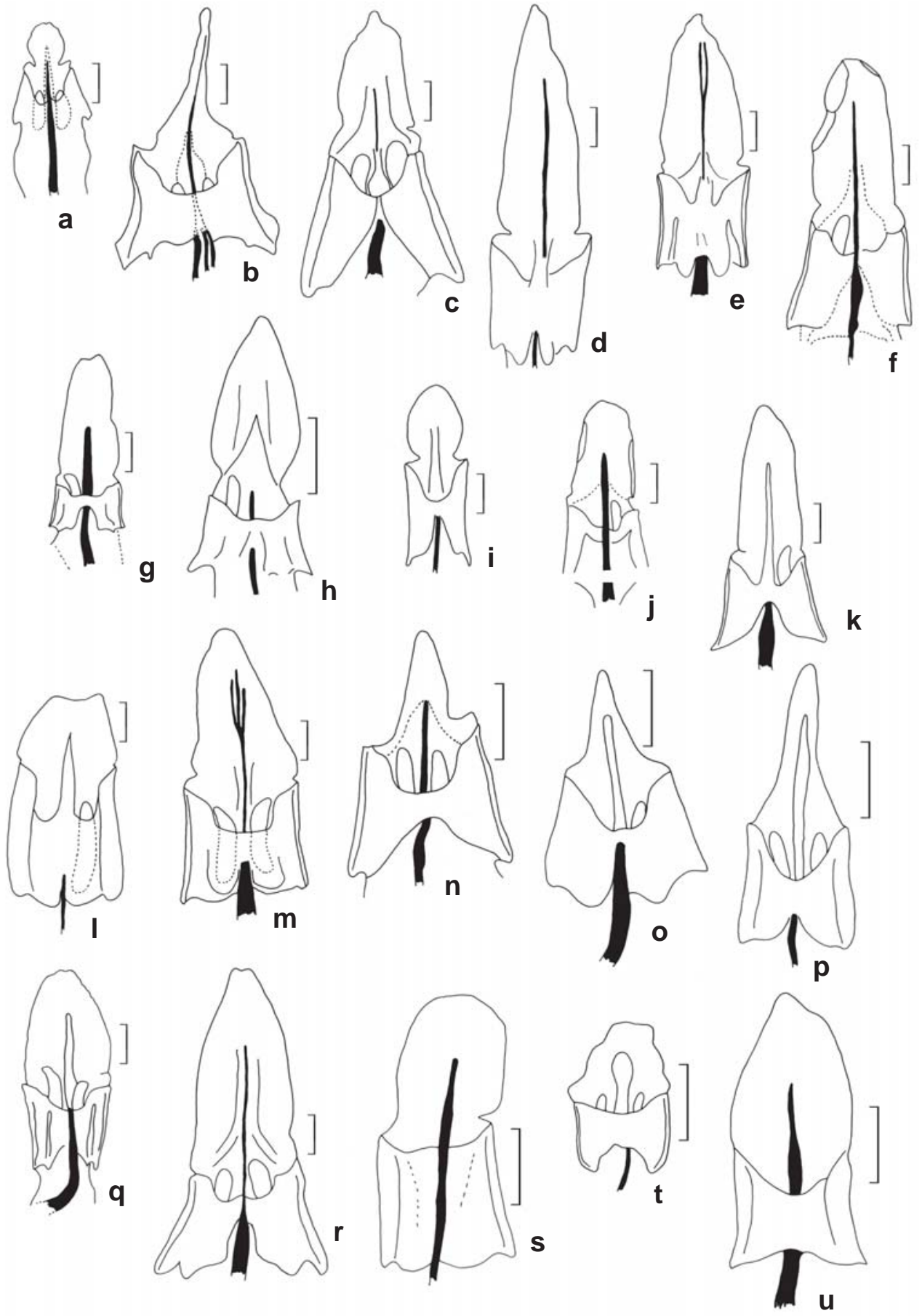

Figura 17 - Vascularização dos estames - a. Oxypetalum alpinum var. alpinum (Sucre 6505); b. O. appendiculatum (Barros 3014); c. O. arachnoideum (Duarte 4774); d. O. banksii subsp. banksii (Marquete 415); e. O. banksii subsp. corymbiferum (Lima 1105); f. O. insigne var. insigne (Pereira 2938); g. O. insigne var. glabrum (Furlan 3239); h. O. insigne var. glaziovii (Ribeiro 914); i. O. jacobinae (Bianchini 462); j. O. lanatum (Farney 1428); k. O. molle (Kuhlmann 1969); 1. O. pachyglossum (Pereira 2938); m. O. pannosum var. pannosum (Marquete 453); n. O. patulum (Emmerich 605); o. O. cordifolium subsp. pedicellatum (Occhioni 1284); p. O. pilosum (Góes 1201); q. O. regnellii (Occhioni 1285); r. O. sublanatum (Lima 1150); s. O. cordifolium subsp. brasiliense (Marquete 447); t. O. glaziovii (Castellanos 25670); u. O. wightianum (Marquete 452). Barra= $500 \mu \mathrm{m}$. 

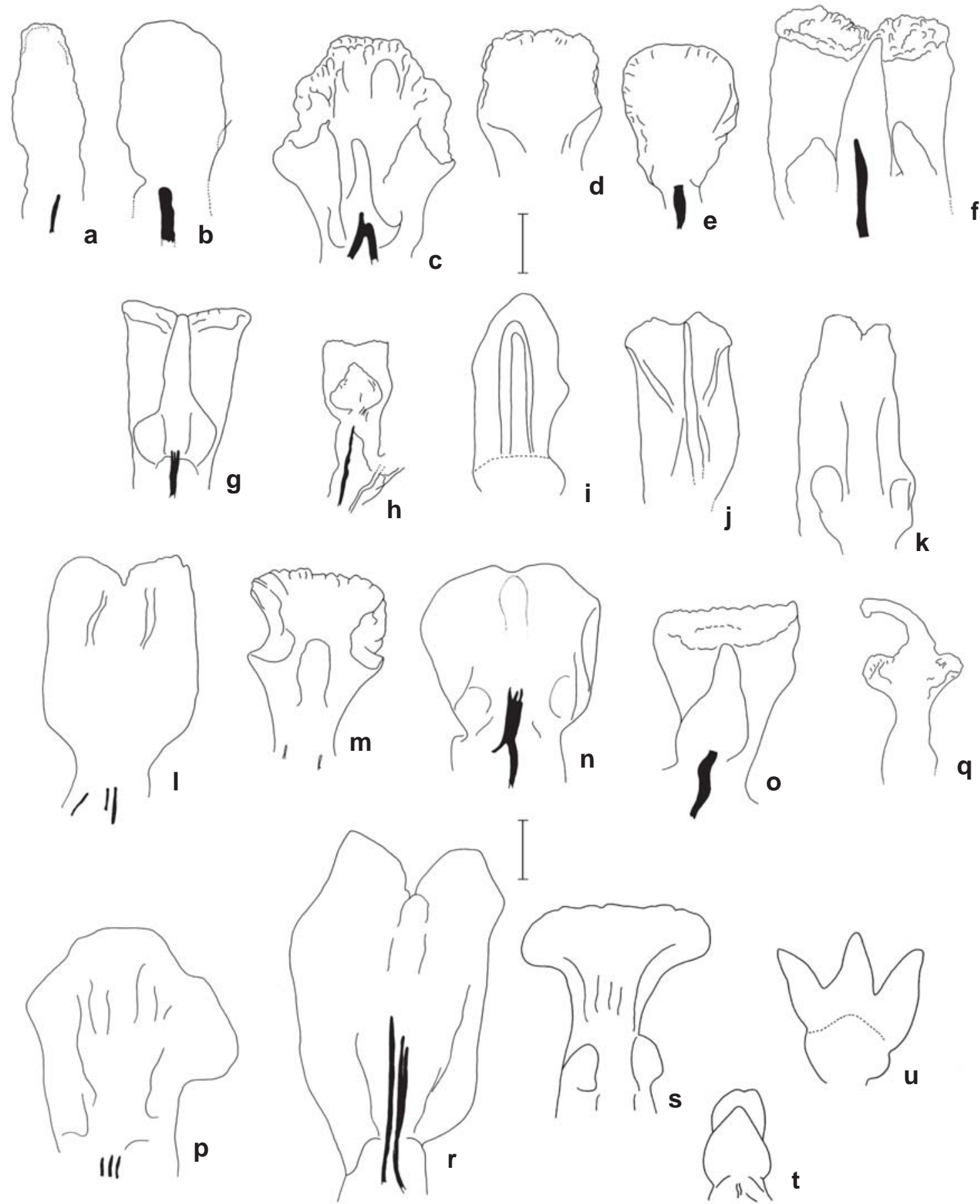

Figura 18 - Vascularização dos segmentos da corona - a. Oxypetalum alpinum var. alpinum (Sucre 6505); b. O. appendiculatum (Barros 3014); c. O. arachnoideum (Duarte 4774); d. O. banksii subsp. banksii (Marquete 415); e. O. banksii subsp. corymbiferum (Lima 1105); f. O. insigne var. insigne (Pereira 2938); g. O. insigne var. glabrum (Furlan 3239); h. O. insigne var. glaziovii (Ribeiro 914); i. O. jacobinae (Bianchini 462); j. O. lanatum (Farney 1428); k. O. molle (Kuhlmann 1969); 1. O. pachyglossum (Pereira 2938); m. O. pannosum var. pannosum (Marquete 453); n. O. patulum (Emmerich 605); o. O. cordifolium subsp. pedicellatum (Occhioni 1284); p. O. pilosum(Goes 1201); q. O. regnelii (Occhioni 1285); r. O. sublanatum (Lima 1150); s. O. cordifolium subsp. brasiliense (Marquete 447); t. O. glaziovii (Castellanos 25670); u. O. wightianum (Marquete 452). Barra $=500 \mu \mathrm{m}$ 


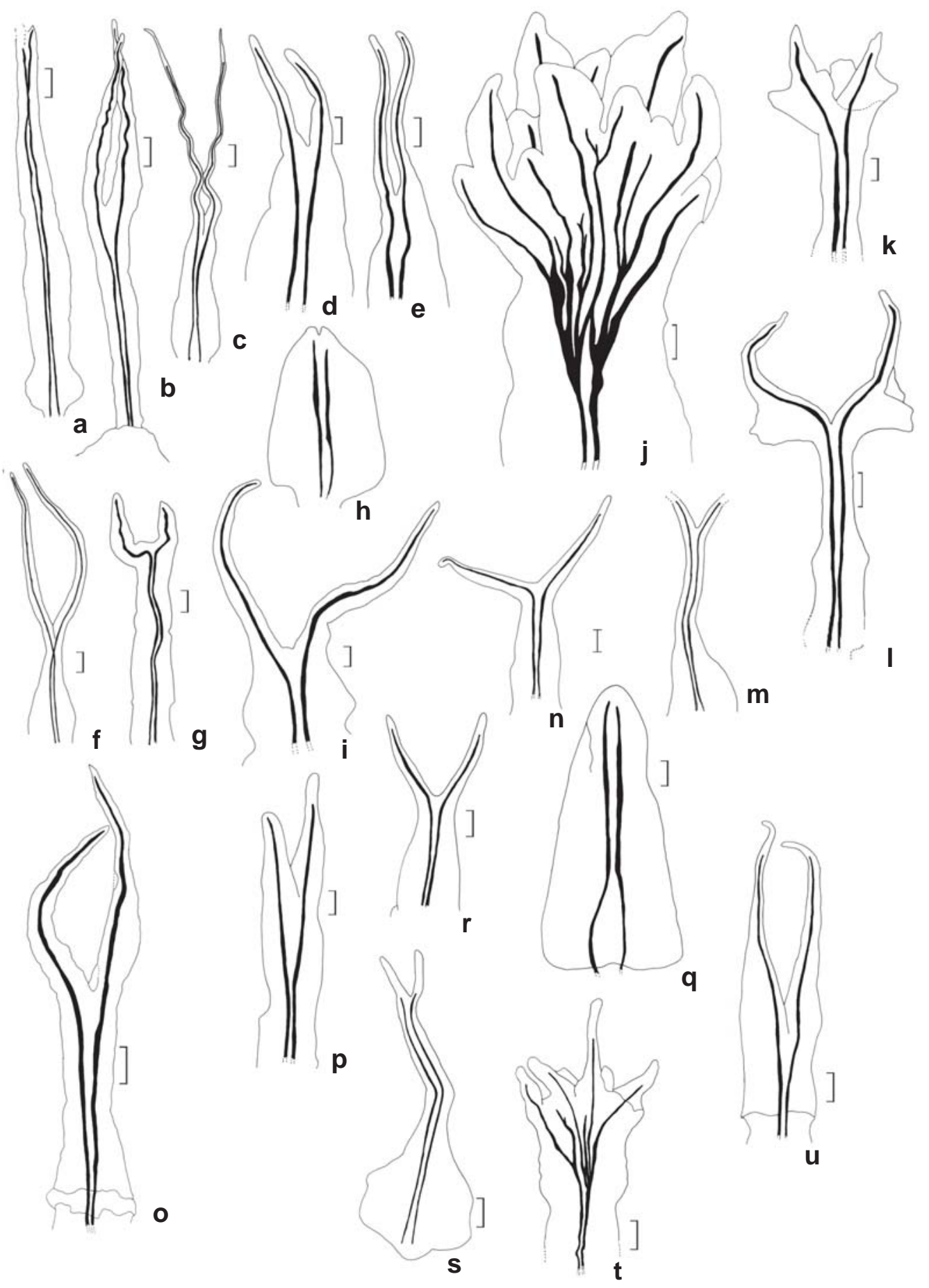

Figura 19 - Vascularização dos apêndices estilares - a. Oxypetalum alpinum var. alpinum (Sucre 6505); b. O. appendiculatum (Barros 3014); c. O. arachnoideum (Duarte 4774); d. O. banksii subsp. banksii (Marquete 415); e. O. banksii subsp. corymbiferum (Lima 1105); f. O. jacobinae (Bianchini 462); g. O. molle (Kuhlmann 1969); h. O. pachyglossum (Pereira 2938 ); i. O. pannosum var. pannosum (Marquete 453); j. O. insigne var. insigne (Occhioni 1219); k. O. insigne var. glaziovii (Ribeiro 914); 1. O. insigne var. glabrum (Furlan 3239); m. O. patulum (Emmerich 605); n. O. cordifolium subsp. pedicellatum (Occhioni 1284); o. O. lanatum (Farney 1428); p. O. pilosum (Goes 1201); q. O. sublanatum (Lima 1150); r. O. cordifolium subsp. brasiliense (Marquete 447); s. O. glaziovii (Castellanos 25670); t. O. regnelii (Occhioni 1285); u. O. wightianum (Marquete 452). Barra=500 $\mu \mathrm{m}$ 

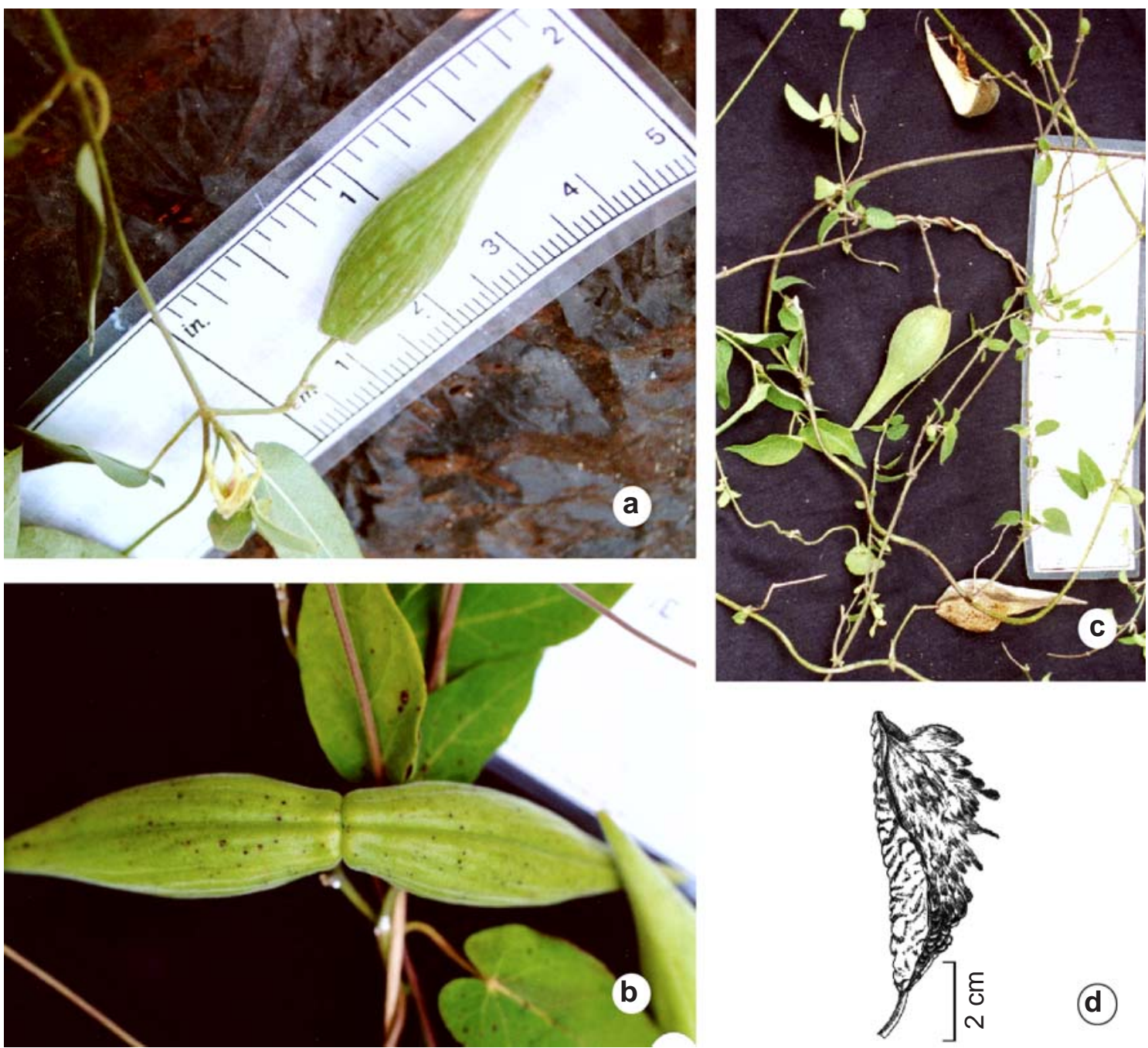

Figura 20 - a-b. Oxypetalum appendiculatum - a. folículo; b. folículos gêmeos (Marquete 436); c. O. cordifolium subsp. brasiliense - folículo maduro e aberto, evidenciando o pericarpo delgado (Marquete 416); d. O. wightianum - fruto (Marquete 452).

espessura de 0,2-0,3 mm (Fig. 20c); apresentam uma sutura deiscente adaxialmente.

Os frutos nas Asclepiadoideae são considerados frutos múltiplos, sendo que cada frutíolo corresponde a um folículo (Barroso et al. 1999).Apenas um, raramente dois, carpelos se desenvolvem. Nesses casos, há presença de um cômpito (Kunze 1991; Vieira 1998) na região dos estiletes sólidos, que possibilita a distribuição de tubos polínicos para os dois carpelos, resultando na produção de folículos gêmeos (Fig. 20b), independentemente da câmara nectarífera que recebeu a polínia (Vieira 1998).
Semente: as sementes, nos táxons estudados, são sempre achatadas, ovadas ou planoconvexas, com face dorsal convexa e ventral côncava. A testa, de cor castanha e verrucosa, possui margens levemente onduladas, na região da micrópila e do hilo, providas de uma coma longa, sedosa e alvescente, com 30-35 mm. O endosperma é denso, cartilaginoso e o embrião, axial, espatulado e espesso, apresenta cotilédones foliáceos, planos ou elípticos, com base levemente cordada; são esbranquiçados, medem 2-2,5 $\times 1,2-1,8 \mathrm{~mm}$ compr. e possuem radícula curta 1-1,2 mm (Fig. 21a-d). A germinação é fanerocotiledonar. 

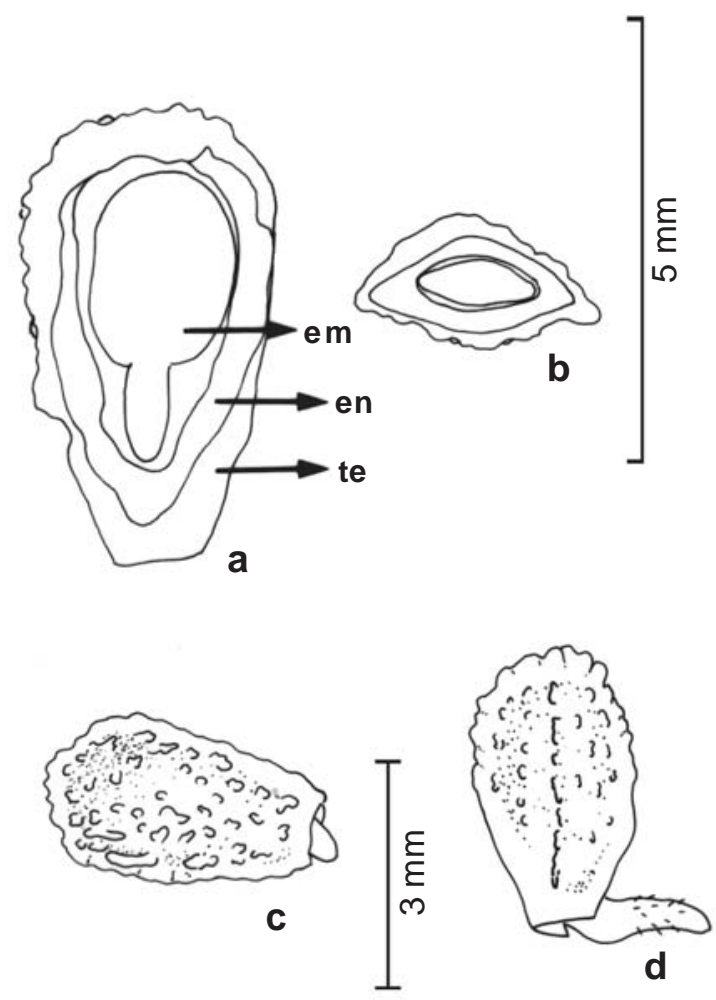

Figura 21 - Sementes de Oxypetalum lanatum - a. corte longitudinal evidenciando a testa (te), endosperma (en) e embrião (em); b. corte transversal; c-d. estágios da germinação da semente (Marquete 353).

A coma é uma estrutura pilosa formada pelo alongamento estrofiolar da testa em torno da micrópila (Barroso et al. 1999). Em Oxypetalum a coma prolonga-se até o ápice do folículo e o número de sementes por frutos é em torno de 100 (Vieira 1998). As sementes distribuem-se no fruto de forma imbricada e prendem-se pelo funículo no resíduo do tecido placentário. Quando o fruto está maduro e se abre, as sementes começam a se desprender desde o ápice; a coma abre-se em forma de um pára-quedas e a semente é carregada pelo vento.

\section{Considerações Finais}

As características mais importantes para a conceituação do gênero Oxypetalum estão relacionadas aos polinários, segmentos da corona e apêndices estilares.

Já os aspectos mais importantes para a delimitação das espécies estudadas encontramse associados aos polinários, aos apêndices estilares, às lacínias da corola, aos segmentos da corona, coléteres sepalares e à forma das folhas.

A análise das inflorescências indicou que o tipo cimóide corimbiforme predomina nas espécies estudadas.

Deve-se salientar que os aspectos anatômicos observados nas espécies $O$. banksii subsp. banksii e $O$. insigne var. insigne correspondem às características gerais mencionadas por Solereder (1908) e Metcalfe \& Chalk (1965) para as Asclepiadoideae, tais como a presença de feixes vasculares bicolaterais e idioblastos cristalíferos nos coléteres nas sépalas. Entre as estruturas típicas da flor das Asclepiadoideae e das famílias da ordem Gentianales figuram os coléteres.

No presente estudo foi observado que a atividade das células secretoras que revestem a cabeça estilar forma os transladores (retináculo e caudículas).

A posição da inserção dos segmentos da corona, a presença ou ausência de dentes e espessamentos, bem como suas diferentes formas (desde pregas, pequenas saliências à formações dentiformes) são caracteres utilizados na identificação das espécies.

$\mathrm{O}$ apêndice estilar também pode ser útil na separação de grupos de espécies, variando desde crateriforme a bífido em diferentes alturas, com lobos lisos, aplanados e com margens trilobadas à levemente denteadas.

A vascularização do cálice e corola mostrou três padrões, definidos pela densidade de nervuras e por suas ramificações.

As coronas, que em Asclepiadoideae geralmente não são vascularizadas, apresentaram em algumas espécies um feixe que atinge a base ou a região mediana do segmento.

Os estames são percorridos por um único feixe, embora em $O$. banksii subsp. corymbiferum e $O$. pannosum var. pannosum o feixe se apresente dividido em dois ou três, nos apêndices membranáceos.

O trabalho contribui com uma melhor compreensão da morfologia e anatomia do 
grupo, elucidando dúvidas taxonômicas, principalmente aquelas que facilitam o reconhecimento dos táxons e, espera-se com a divulgação destas informações subsidiar futuras abordagens filogenéticas.

\section{Agradecimentos}

Ao Conselho Nacional de Desenvolvimento Científico e Tecnológico (CNPq) pelas bolsas concedidas aos autores. Ao Pesquisador Osnir Marquete, pelas microfotografias referentes aos aspectos anatômicos da flor. Aos ilustradores Paulo Ormindo e Aline Souza Lima. Ao biólogo Paulo Botelho de Macedo pela paciência e grande ajuda na arte gráfica. À bióloga Aline Cardoso Cerqueira pela ajuda nas atividades de laboratório. Ao Dr. Rodrigo Capaz pela versão em inglês do resumo. Ao Laboratório de Ultraestrutura Celular Hertha Meyer, Instituto de Biofísica Carlos Chagas Filho, CCS/UFRJ.

\section{REFERÊNCIAS BibliográfiCAS}

Appezzato-da-Glória, B. \& Estelita, M. E. M. 2000. Development, structure and distribution of colleters in Mandevilla illustris and M.velutina (Apocynaceae). Revista Brasileira Botânica 23(2): 113-120.

Arekal, G. D. \& Ramakrishna, T. M. 1980. Extrafloral nectaries of Calotropis gigantea and Wattakaka volubilis. Phytomorphology 30: 303-306.

Barroso, G. M.; Peixoto, A. L.; Costa, C. G.; Falcão, C. L. I.; Guimarães, E. F. \& Lima, H. C. 1986. Sistemática de Angiospermas do Brasil 3. Universidade Federal de Viçosa, Viçosa. Pp. 16-52.

Barroso, G. M.; Morim, M. P.; Peixoto, A. L. \& Ichaso, C. L. F. 1999. Frutos e sementes, morfologia aplicada à sistemática de Dicotiledôneas. Universidade Federal de Viçosa, Viçosa, $441 \mathrm{p}$.

Decaisne, J. 1844 Asclepiadaceae. In: Candolle, A. L. P. P. Prodromus systematis naturalis regni vegetabilis... Paris (Treuttel \& Würtz), Strasbourg, London, 8: 490-665.
Endress, P. K. 1994. Diversity and evolutionary biology of tropical flowers. Cambridge University Press. Pp. 511. \& Bruyns, P. V. 2000. A revised classification of Apocynaceae s.1. Botanical Review 66(1): 1-56.

Fahn, A. 1979. Secretory tissues in plants. Academia Press, London, 302p.

Fontella-Pereira, J. 1965. Contribuição ao estudo das Asclepiadaceae brasileiras, 2. Sellowia 17: 61-76.

. 1977. Revisão taxonômica do gênero Tassadia Decaisne (Asclepiadaceae). Arquivo Jardim Botânico Rio de Janeiro 21: 235-392.

\& Valente, M. C. 1969. Contribuição ao estudo das Asclepiadaceae brasileiras, IV. Espécies novas afins à Ditassa hastata Decne. Loefgrenia 31: 1-6.

\& Marquete, N. F. S. 1971. Estudos em Asclepiadaceae, II. Sobre a identidade de Bustelma warmingii Fourn. Museu Botânico Municipal Curitiba 1: 1-6.

Fontella-Pereira, J. \& Marquete, N. F. S. 1974. Estudos em Asclepiadaceae, V. Uma nova espécie de Blepharodon Decne. Boletim Museu Botânico 18:1-3. $\&$ 1975. Estudos em Asclepiadaceae, VI. Uma nova espécie de Astephanus R.Br. Bradea 3: 9-12.

; Valente, M. C. \& Alencastro, F. M. M. R. 1971. Contribuição ao estudo das Asclepiadaceae brasileiras, V. Estudo taxonômico e anatômico de Oxypetalum banksii Roem. \& Schult. Rodriguésia 26(38): 261-282.

\& Schwarz, E. A. 1984. Contribuição ao estudo das Asclepiadaceae brasileiras, XXI. Asclepiadaceae do município de Ouro Preto, estado de Minas Gerais - uma sinopse. Boletim Museu Botânico Kuhlmann 7(2): 63-127.

Fournier, E. 1885. Asclepiadaceae. In: Martius, C. F. P. von; Eichler, A. W. \& Urban, I. Flora brasiliensis ... München, Wien, Leipzig, 6(4): 189-332. 
Galil, J. \& Zeroni, M. 1969. On the organization of the pollinium in Asclepias curassavica. Botanical Gazete 130(1): 1-4.

Hayat, M. A. 1981. Principles and techniques of eletron microscopy. Edward Arnold, London, 522p.

Hoehne, F. C. 1916. Monografia das Asclepiadaceae brasileiras (Monographia Asclepiadacearum Brasiliensium). Oxypetalum et Calostigma. Comissão de Linhas Telegráficas, Estratégicas de Matto Grosso ao Amazonas. Publ. 38, fasc. 1: 1-131, et ibid. Fasc. 2: 1-13.

Holmgren, P. K.; Holmgren, N. H. \& Barnett, L. C. 1990. Index Herbariorum. Part. 1: The Herbario of the World Regnum vegetabile. $8^{\mathrm{a}}$ ed. New York Botanical Garden, New York, 693p.

Johansen, D. 1940. Plant microtechnique. McGraw-Hill, New York, 523p.

Kunze, H. 1990. Morphology and evolution of the corona in Asclepiadaceae and related families. Tropische und Subtropische Pflanzenwelt 76: 1-49.

1991. Structure and function in asclepiad pollination. Plant Systematic Evolution 176: 227-253.

1996. Morphology of the stamen in the Asclepiadaceae and its systematic relevance. Botanische Jahrbücher für Systematik 118: 547-579.

Liede, S. 1996. Anther differentiation in the Asclepiadaceae-Asclepiadeae: form and function. In: W. G. D'Arcy \& R. C. Keating (eds.). The anther: form, function and phylogeny. Cambridge University Press. Pp. 221-235.

\& Kunze, H. 1993. A descriptive system for corona analysis in Asclepiadaceae and Periplocacceae. Plant Systematic Evolution 185: 275-284.

\& Weberling, F. 1995. On the inflorescence structure of Asclepiadaceae. Plant Systematic Evolution 197: 99-109.

Luque, R.; Sousa, H. C. \& Kraus, J. E. 1996. Métodos de coloração de Roeser (1972) modificado e Kropp (1972) visando a substituição do azul de astra por azul de alcião $8 \mathrm{G} \mathrm{S}$ ou $8 \mathrm{GX}$. Acta Botanica Brasilica 10(2): 199-212.

Malme, G. O. A. 1900a. Die Systematische Gliederung der Gattung Oxypetalum R. Br. Oefvers. Kongl. Svenska VetenskapsAkademiens Handlingar 7: 843-865.

1900b. Die Asclepiadaceen des Regnell'schen Herbars. Kongl. Svenska Vetenskaps-Akademiens Handlingar 34(7): 1-102.

1927. Asclepiadaceae Dusenianae in Paraná collectae. Arkiv för Botanik 21A(3): 1-48.

1939. Asclepiadaceae austroamericanae novae vel minus cognitae. Arkiv för Botanik 29A(13): 1-5.

Marquete, N. F. S. 2003. O gênero Oxypetalum R.Br. (AsclepiadoideaeApocynaceae) no estado do Rio de Janeiro, Brasil. Tese de Doutorado. Universidade Federal, 313p.

Marquete, N. F. S.; Fontella-Pereira, J \& Valente, M. C. 2007. Asclepiadoideae (Apocynaceae) from southeastern Brazil. I. The genus Oxypetalum from Rio de Janeiro State, Brazil. Annals of the Missouri Botanical Garden 94(2): 435-462.

Metcalfe, C. R. \& Chalk, L. 1965. Anatomy of Dicotyledons. Vol. 2. Asclepiadaceae. Claredon Press, Oxford. Pp. 917-925.

Meyer, T. 1944. Asclepiadaceae. In: Descole, H. R. Genera et species plantarum argentinarum. Vol. 2. Guilherme Kraft, Buenos Aires, 273p.

Occhioni, P. 1956. Contribuição ao estudo do gênero Oxypetalum, com especial referência às espécies do Itatiaia e Serra dos Órgãos. Arquivo Jardim Botânico Rio de Janeiro 14: 37-210.

Payne, W. W. 1978. A glossary of plant hair terminology. Brittonia 30(2): 239-255.

Puri, V. 1952. Placentation in Angiosperms. Botanical Review 18(9): 603-651.

Purvis, M.; Collier, D. \& Walls, D. 1964. Laboratory techniques in botany. Butterworths, London, 371 p. 
Rapini, A., Mello-Silva, R. \& Kawasaki, M. L. 2001. Asclepiadoideae (Apocynaceae) da Cadeia do Espinhaço de Minas Gerais, Brasil. Boletim de Botânica da Universidade de São Paulo 19: 55-169.

Rio, M. C. S.; Castro, M. M. \& Kinoshita, L. 2002. Distribuição e caracterização anatômica dos coléteres foliares de Prestonia coalita (Vell.) Woodson (Apocynaceae). Revista Brasileira de Botânica 25(3): 339-340.

Rosatti, T. J. 1989. The genera of suborder Apocninéae (Apocynaceae and Asclepiadaceae) in the Southeastern United States. Journal Arnold Arbor 70: 443-514.

Sass, J. E. 1940. Elements of botanical microtechnique. McGraw-Hill, New York, London, 222p.

Schumann, K. 1895. Asclepiadaceae. In: Engler, H. G. A. \& Prantl. K. A. E. (eds.). Die natürlichen flanzenfamilien ... Vol. 4. Leipzig (Wilhelm Engelmann). Pp. 189306.

Schwarz, E. A. \& Furlan, A. 2002. Coléteres foliares de Oxypetalum R.Br. (Asclepiadoideae, Apocynaceae). Aspectos ultraestruturais e anatômicos úteis à taxonomia das espécies do estado do Paraná. Acta Biológica Paranaense 31(1,2,3,4): 79-97.
Solereder, H. 1908. Systematic anatomy of Dicotyledons. Vol. I. Claredon Press, Oxford. Pp. 534-537.

Troll, J. 1964. Die Infloreszenzen. Vol. 1. Gustav Fischer Verlag, Stuttgart, 615p.

Valente, M. C. 1977. A flor de Oxypetalum banksii Roem. et Schult. subsp. banksii: Estudo de anatomia e vascularização (Asclepiadaceae). Rodriguésia 29(43): 161-284.

1995. Matelea maritima subsp. ganglinosa (Vell.) Font. Anatomia e vascularização floral (Asclepiadaceae). Arquivos do Jardim Botânico do Rio de Janeiro 33(1): 75-98.

; Fontella-Pereira, J. \& Alencastro, F. M. M. R. 1971. Contribuição ao estudo das Asclepiadaceae brasileiras, VII. Estudos taxonômico e anatômico de Oxypetalum banksii Roem. et Schult. subsp. corymbiferum (Fourn.) Font. \& Val., comb. nov. Anais da Academia Brasileira de Ciência 43(1): 177-189.

Vieira, M. F. 1998. Biologia reprodutiva de espécies de Oxypetalum (Asclepiadaceae), na região de Viçosa, $M G$, Sudeste brasileiro. Tese de Doutorado. Universidade Estadual de Campinas. Campinas.

Weberling, F. 1989. Morphology of flowers and inflorescences. Univerty Press Cambridge, Cambridge, 405p. 